\title{
Nitrogen Removal from Natural Gas
}

\author{
Phase II Draft Final Report \\ Contract Number DE-AC21-95MC32199--02 \\ Contract Period: July 29, 1996 - December 31, 1999 \\ prepared by \\ Membrane Technology and Research, Inc. \\ 1360 Willow Road \\ Menlo Park, CA 94025 \\ December 22, 1999 \\ for \\ the U.S. Department of Energy \\ Morgantown Energy Technology Center \\ Morgantown, WV
}

Contributors to this Report:

K.A. Lokhandwala

M.B. Ringer

T.T. Su

Z. He

I. Pinnau

J.G. Wijmans

A. Morisato

K. Amo

A. Da Costa

R.W. Baker

R. Olsen

H. Hassani

T. Rathkamp 


\section{SUMMARY}

The objective of this project was to develop a membrane process for the denitrogenation of natural gas. Large proven reserves in the Lower-48 states cannot be produced because of the presence of nitrogen. To exploit these reserves, cost-effective, simple technology able to reduce the nitrogen content of the gas to $4-5 \%$ is required. Technology applicable to treatment of small gas streams (below 10 MMscfd) is particularly needed.

In this project membranes that selectively permeate methane and reject nitrogen in the gas were developed. Preliminary calculations show that a membrane with a methane/nitrogen selectivity of 3 to 5 is required to make the process economically viable. A number of polymer materials likely to have the required selectivities were evaluated as composite membranes. Polyacetylenes such as poly(1-trimethylsilyl-1-propyne) [PTMSP] and poly(4-methyl-2-pentyne) [PMP] had high selectivities and fluxes, but membranes prepared from these polymers were not stable, showing decreasing flux and selectivity during tests lasting only a few hours. Parel, a poly(propylene oxide allyl glycidyl ether) had a selectivity of 3 at ambient temperatures and 4 or more at temperatures of $-20^{\circ} \mathrm{C}$. However, Parel is no longer commercially available, and we were unable to find an equivalent material in the time available. Therefore, most of our experimental work focused on silicone rubber membranes, which have a selectivity of 2.5 at ambient temperatures, increasing to 3-4 at low temperatures.

Silicone rubber composite membranes were evaluated in bench-scale module tests and with commercial-scale, 4-inch-diameter modules in a small pilot plant. Over six days of continuous operation at a feed gas temperature of -5 to $-10^{\circ} \mathrm{C}$, the membrane maintained a methane/nitrogen selectivity of about 3.3. Based on the pilot plant performance data, an analysis of the economic potential of the process was prepared. We conclude that a stand-alone membrane process is the lowest-cost technology for small gas streams containing less than $10 \%$ nitrogen. The membrane process can recover more than $60-70 \%$ of the hydrocarbon content of the gas at a cost of $\$ 0.60$ $0.70 / \mathrm{Mscfd}$. The capital cost of the process is about $\$ 100-200 / \mathrm{Mscf}$. A number of small operators appear to be ready to use the technology if these costs can be demonstrated in the field.

A second, and perhaps better, application of the technology is to combine the membrane process with a cryogenic process to treat large gas streams containing 10-20\% nitrogen. The combination process achieves significant synergies. The membrane process performs a bulk separation of the gas, after which the cryogenic process treats the membrane residue (nitrogen-enriched) gas to recover more methane. Overall, hydrocarbon recoveries are greater than $95 \%$. The capital cost of the combination process is lower than that of either process used alone and the processing costs are in the range $\$ 0.30-0.40 / \mathrm{Mscf}$. This operating cost would be attractive to many gas producers. MTR is collaborating with a producer of cryogenic systems to further develop the combination process.

A number of innovations in membrane process designs were made during the project; four U.S. patents covering various aspects of the technology were filed and issued. 
SUMMARY $\ldots \ldots \ldots \ldots \ldots \ldots \ldots \ldots \ldots \ldots \ldots \ldots \ldots \ldots \ldots \ldots \ldots \ldots$

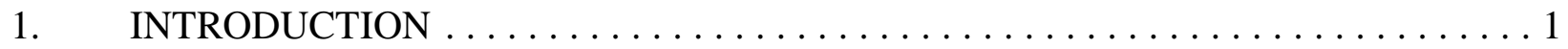

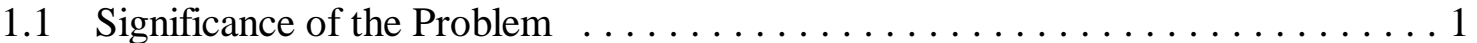

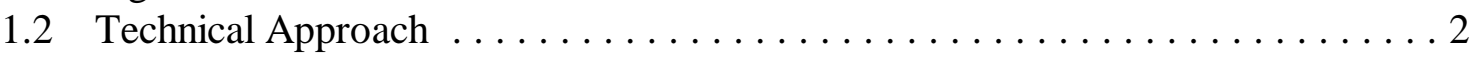

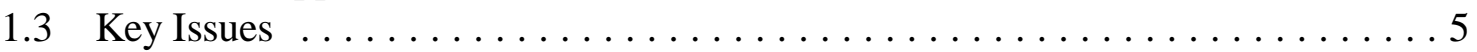

2. PHASE I OBJECTIVES AND ACHIEVEMENTS $\ldots \ldots \ldots \ldots \ldots \ldots \ldots \ldots$

3. PHASE II OBJECTIVES AND ACHIEVEMENTS $\ldots \ldots \ldots \ldots \ldots \ldots \ldots$

4. EXPERIMENTAL TECHNIQUES AND PROCEDURES $\ldots \ldots \ldots \ldots \ldots \ldots \ldots$

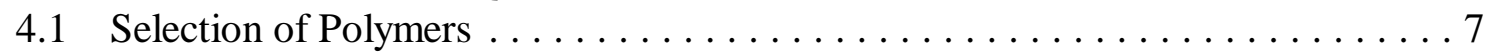

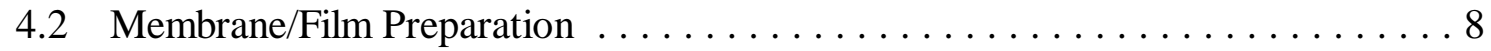

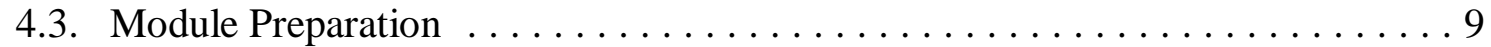

4.4 Laboratory Module Tests . . . . . . . . . . . . . . . . . . . 10

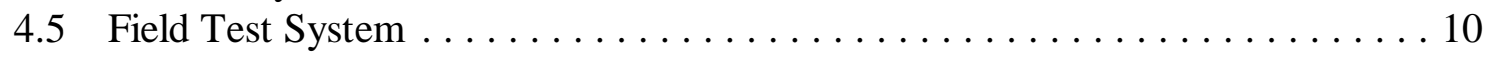

5. EXPERIMENTAL RESULTS $\ldots \ldots \ldots \ldots \ldots \ldots \ldots \ldots \ldots \ldots \ldots \ldots \ldots$

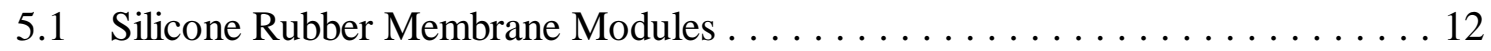

5.2 PMP Membrane Module . . . . . . . . . . . . . . . . . . . . . . 19

5.3 Parel Membrane Module . . . . . . . . . . . . . . . . . . . . . . 21

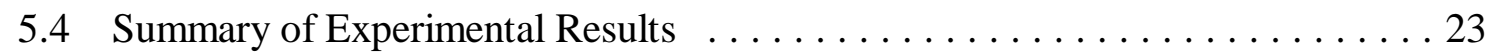

6. TECHNICAL AND ECONOMIC ANALYSIS $\ldots \ldots \ldots \ldots \ldots \ldots \ldots \ldots \ldots \ldots$

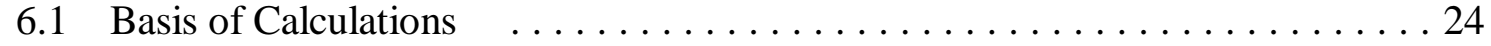

6.2 Case Studies/Customer Contact . . . . . . . . . . . . . . . . . . . . 39

6.3 Patents ............................ 40

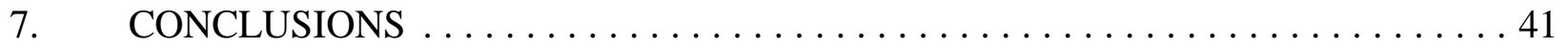

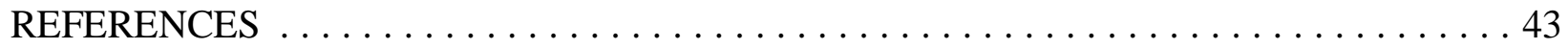




\section{List of Figures}

Figure 1. Simplified block diagram of a low-temperature membrane process for natural gas denitrogenation coupled with higher hydrocarbon liquid (NGL) recovery . . . . . . 3

Figure 2. Schematic diagram of an MTR composite membrane $\ldots \ldots \ldots \ldots \ldots \ldots$

Figure 3. Schematic of a spiral-wound membrane module $\ldots \ldots \ldots \ldots \ldots \ldots \ldots \ldots$

Figure 4. Schematic diagram of module winding apparatus $\ldots \ldots \ldots \ldots \ldots \ldots$

Figure 5. Flow diagram of the bench-scale test apparatus for determining module

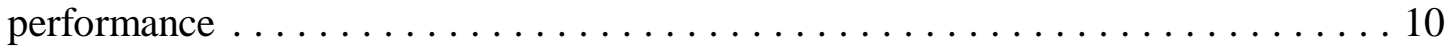

Figure 6. Simplified flow schematic of the membrane field test unit $\ldots \ldots \ldots \ldots \ldots \ldots$

Figure 7. Comparison of methane/nitrogen selectivity for silicone rubber membrane stamps, small modules tested in the laboratory-scale system and a large 4-inch module tested

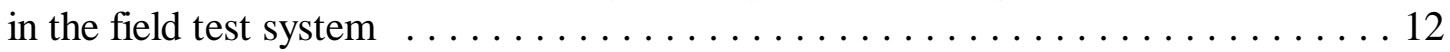

Figure 8. Feed flow rate as a function of time for the five-day test on the 4-inch silicone rubber

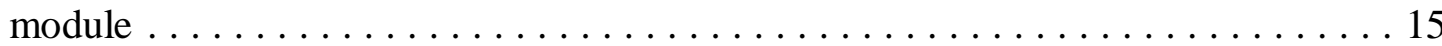

Figure 9. Feed pressure as a function of time for the five-day test on the 4-inch silicone rubber module . . . . . . . . . . . . . . . . . . . . . . . . . . . . . . . 16

Figure 10. Feed temperature as a function of time for the five-day test on the 4-inch silicone

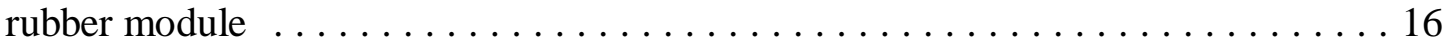

Figure 11. Feed, residue and permeate nitrogen content as a function of time during the long-

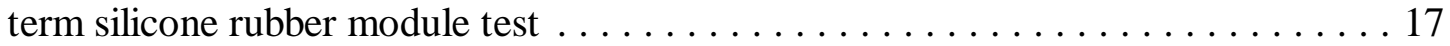

Figure 12. Pressure-normalized fluxes of methane and nitrogen as a function of time during the

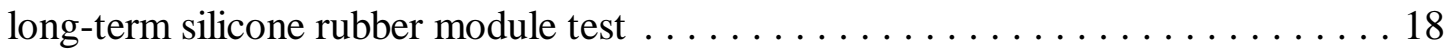

Figure 13. Methane/nitrogen selectivity as a function of time during the long-term silicone rubber

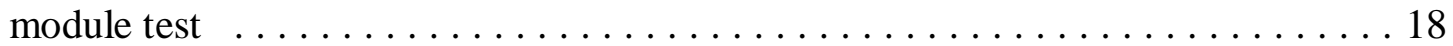

Figure 14. Effect of feed pressure and temperature on the PMP module methane/nitrogen

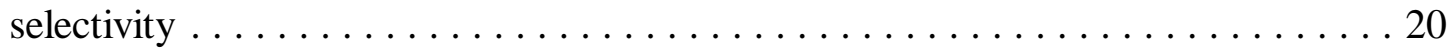

Figure 15. Comparison of the PMP module selectivity and PTMSP membrane selectivity . . . 21 


\section{List of FIgures - Continued}

Figure 16. Methane/nitrogen selectivity as a function of feed temperature at feed pressures of $400,600,800$ and 1,000 psia for the Parel module . . . . . . . . . . 22

Figure 17. Comparison of methane/nitrogen selectivities for all the modules evaluated in the

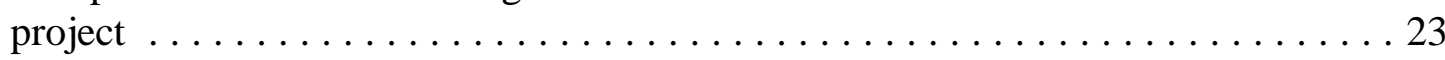

Figure 18. Process flow diagram for the stand-alone membrane process to separate nitrogen from

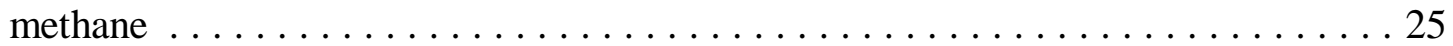

Figure 19. Simplified flow scheme of a combination membrane/cryogenic separation process . 26

Figure 20 . Flow schematic for combined membrane/cryogenic process $\ldots \ldots \ldots \ldots$

Figure 21. Impact of membrane selectivity, product discharge pressure, and feed gas nitrogen

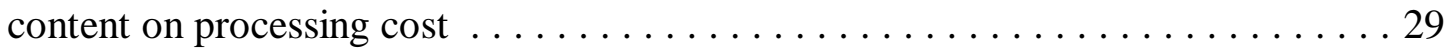

Figure 22. Effect of nitrogen feed content on recovery of hydrocarbons from the feed gas . . . 30

Figure 23. Comparison of the capital cost of three process configurations: a stand-alone membrane process, a stand-alone cryogenic process, and a combined

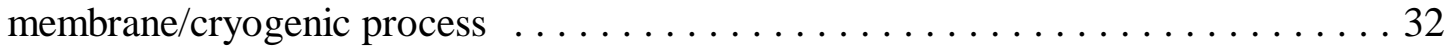

Figure 24. Comparison of processing costs for three processes: a stand-alone membrane process, a stand-alone cryogenic process, and a combined membrane/cryogenic process . . . 32

Figure 25. Comparison of processing costs as a function of feed nitrogen content for three processes: a stand-alone membrane process, a stand-alone cryogenic process, and a combined membrane/cryogenic process $\ldots \ldots \ldots \ldots \ldots \ldots \ldots \ldots \ldots \ldots \ldots \ldots \ldots \ldots$

Figure 26. Combined membrane/adsorption process for methane/nitrogen separation . . . . . 34

Figure 27. Process combining a single-stage membrane system with an absorption process for

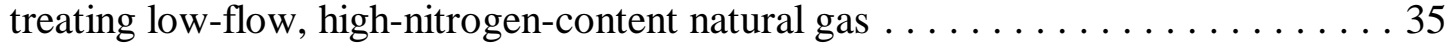

Figure 28. Reserves volume as a function of nitrogen concentration in natural gas . . . . . 36 


\section{List of Tables}

Table 1. Processes Currently Used or Under Development for Removal of Nitrogen from

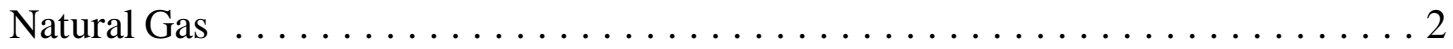

Table 2. Data Obtained from Tests in the Laboratory-Scale Unit Using a 2 1/2 -inch Module . 13

Table 3. Data obtained from the Five-Day Continuous Testing in the Field Test Unit Using the 4-inch Membrane Module . . . . . . . . . . . . . . . . . . . . . . . . . 14

Table 4. PMP Module Permeation Data . . . . . . . . . . . . . . . . . . . . . . . . . . . . . 19

Table 5. Summary of Parel Module Test Results $\ldots \ldots \ldots \ldots \ldots \ldots \ldots \ldots \ldots \ldots$

Table 6. Operating Conditions and Feed Gas Compositions Used for ChemCad III Process

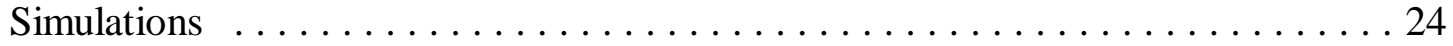

Table 7. Capital and Operating Costs of Combination Membrane/Cryogenic Process . . . . . 28

Table 8. Distribution of Non-Associated Gas with 4\% or More Nitrogen in 1988 Reserves . 36

Table 9. Plants Installed with Nitrogen Rejection Units in the United States Before 1985 . . 37

Table 10.Plants Installed with Nitrogen Rejection Units in the United States by the Late $1980 \mathrm{~s}$. . . . . . . . . . . . . . . . . . . . . . . . . . . . . 37

Table 11.Plants Installed with Nitrogen Rejection Units in the United States in the 1990s _. . 38

Table 12. List of Companies Contacted During Project. . . . . . . . . . . . . . . 39 


\section{INTRODUCTION}

\subsection{Significance of the Problem}

The Energy Information Administration has estimated U.S. reserves of natural gas to be about 165 trillion cubic feet (TCF). The annual demand for natural gas has been steadily increasing over the past decade and is expected to increase further from about 22 TCF presently to more than 27 TCF by 2005. This increased demand will require increased production of gas from the existing proven reserves. A significant proportion of the gas reserves are low quality due to the presence of nitrogen. To meet future needs these low-quality fields will have to be tapped, increasing the proportion of low-quality gas in the gas supply. ${ }^{1}$ Less expensive treatment technology is required to allow these reserves to be economically produced. In addition much of today's gas production is from large, accessible fields, whereas new production will be increasingly from small, remote or offshore fields. As a result, technology able to treat small gas streams is needed. Studies performed by the Gas Research Institute (GRI Executive Summary, March, 1993) ${ }^{2}$ show that $14 \%$ (or about 19 TCF) of known reserves in the United States are subquality due to a high nitrogen content. Nitrogencontaminated natural gas has a low Btu value and has to be upgraded by removing the nitrogen. In many cases, such reserves cannot currently be exploited because of the lack of suitable nitrogenremoval technology. Processes applicable to small gas streams are particularly needed. ${ }^{19}$

In response to the problem, Membrane Technology and Research, Inc. (MTR) is developing a membrane process to remove nitrogen from natural gas. Currently, about 30 natural gas plants incorporating denitrogenation are operating in the United States. ${ }^{3}$ Of these, 24 use a cryogenic process and the remainder use pressure swing adsorption (PSA). Table 1 summarizes the characteristics of the principal processes now in use or under development: cryogenics, PSA, lean oil absorption, and nitrogen absorption. 
Table 1. Processes Currently Used or Under Development for Removal of Nitrogen from Natural Gas. $^{3,4,5}$

\begin{tabular}{||l|l|l|l||}
\hline \multicolumn{1}{|c|}{ Process (Status) } & Method of Separation & \multicolumn{1}{|c||}{ Application } & \multicolumn{1}{c|}{ Comments } \\
\hline $\begin{array}{l}\text { Cryogenic Distillation } \\
\text { (Proven commercially) }\end{array}$ & $\begin{array}{l}\text { Condensation and } \\
\text { distillation at cryogenic } \\
\text { temperatures }\end{array}$ & $\begin{array}{l}\text { Typically high-flow- } \\
\text { rate applications }\end{array}$ & $\begin{array}{l}\text { High methane recovery. } \\
\text { Significant pretreatment } \\
\text { and compression costs. } \\
\text { High capital costs. }\end{array}$ \\
\hline $\begin{array}{l}\text { Pressure Swing } \\
\text { Adsorption (PSA) } \\
\text { Limited commercial } \\
\text { success) }\end{array}$ & Adsorption of methane & $\begin{array}{l}\text { Generally small to } \\
\text { medium flow rates }\end{array}$ & $\begin{array}{l}\text { Pretreatment required. } \\
\text { High capital and } \\
\text { compression costs. High } \\
\text { operating costs. } \\
\text { Moderate methane } \\
\text { recovery. }\end{array}$ \\
\hline $\begin{array}{l}\text { Lean Oil Absorption } \\
\text { New process) }\end{array}$ & $\begin{array}{l}\text { Absorption of methane } \\
\text { in chilled hydrocarbon } \\
\text { oil }\end{array}$ & $\begin{array}{l}\text { Suitable for high } \\
\text { nitrogen content } \\
\text { streams }\end{array}$ & $\begin{array}{l}\text { High capital costs. } \\
\text { Processing costs significant. } \\
\text { Need to absorb bulk of } \\
\text { methane increases } \\
\text { equipment size and } \\
\text { compression requirements. }\end{array}$ \\
\hline $\begin{array}{l}\text { Nitrogen Absorption } \\
\text { Research stage) }\end{array}$ & $\begin{array}{l}\text { Selective absorption of } \\
\text { nitrogen in chelating } \\
\text { solvent }\end{array}$ & $\begin{array}{l}\text { No methane recompression } \\
\text { needed. Stability of solvent } \\
\text { suspect. }\end{array}$ \\
\hline
\end{tabular}

Operating costs for cryogenic processes, the only technology used on any scale, vary with stream composition, but are in the range \$0.30-0.50/Mscf for plants handling $75 \mathrm{MMscfd}$ and increase to more than $\$ 1.00 /$ Mscf for plants handling 2 MMscfd.

Membrane processes have also been considered for natural gas denitrogenation. MTR has determined that to make a membrane process economically viable, a methane-selective membrane is required. The challenge is to develop a stable membrane with sufficient selectivity for methane from nitrogen to make the process technically and economically viable. This report describes MTR's approach and the experimental results obtained and gives a technical and economic analysis of the process.

\subsection{Technical Approach}

Our approach to denitrogenation of subquality natural gas to pipeline specifications is to use methanepermeable membranes in the process illustrated in Figure 1. In this process the incoming pressurized feed gas is cooled to condense $\mathrm{C}_{3+}$ hydrocarbons, which are recovered as natural gas liquids (NGL). The cold gas then passes across the surface of a membrane that selectively permeates methane. The low-pressure permeate gas, containing less than $4 \%$ nitrogen, passes to a compressor that repressurizes the gas. The high-pressure, nitrogen-rich residue gas is expanded through a Joule Thompson (J-T) valve; the refrigeration produced is used to cool the incoming feed gas. 
The three main features of the process are:

- Use of high-performance methane-permeable membranes at low temperatures to separate the feed gas stream into a methane-rich product stream and a nitrogen-rich waste gas stream.

- Expansion of the waste nitrogen stream in a J-T valve to provide cooling of the feed gas without any external refrigeration.

- Recovery of the valuable $\mathrm{C}_{3}+$ higher hydrocarbons (NGL) from the high-pressure feed stream by condensation, using cooling provided by the cold nitrogen-rich waste gas.

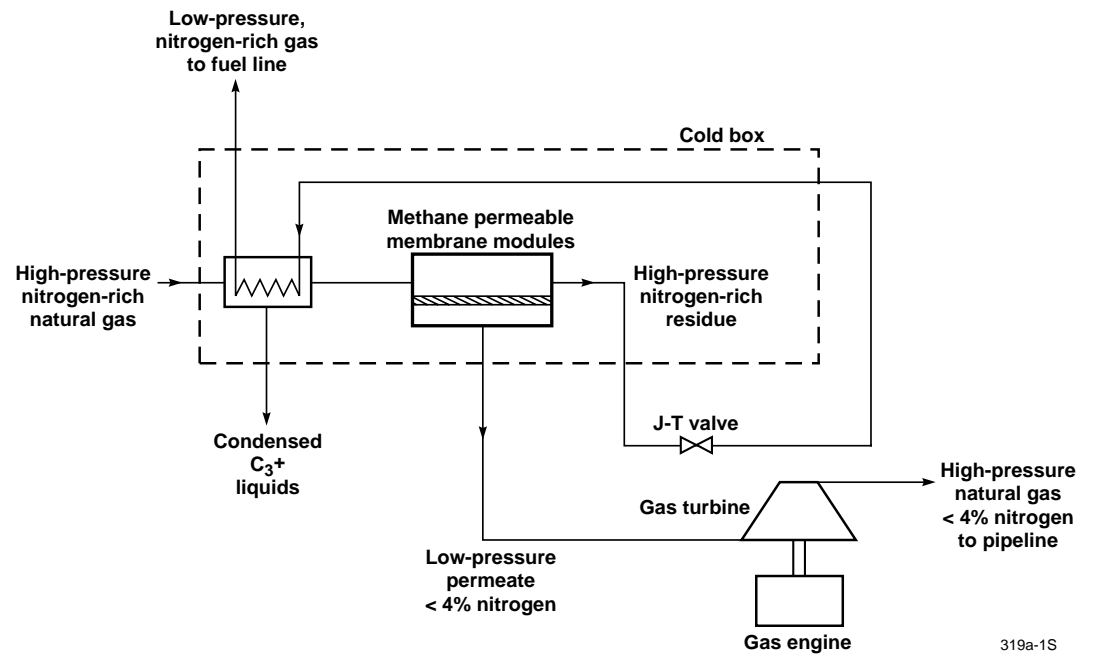

Figure 1. Simplified block diagram of a low-temperature membrane process for natural gas denitrogenation coupled with higher hydrocarbon liquid (NGL) recovery.

The low-pressure, nitrogen-rich gas will provide the fuel required to power the gas engine, while the condensed natural gas liquids (NGL) and the high-pressure natural gas will be the revenue-producing products. Combination processes, involving integration of the membrane system with cryogenic or PSA systems can also be used for larger streams or streams containing higher nitrogen content from which maximum methane recovery is desirable.

The process illustrated in Figure 1 requires methane-permeable membranes with a methane/nitrogen selectivity of 3 to 5 . In Phase I of the project the feasibility of achieving these selectivities at temperatures of -20 to $-50^{\circ} \mathrm{C}$ was demonstrated. A brief discussion of the factors that determine membrane selectivity is given below.

Synthetic polymer membranes separate gas or vapor mixtures because the components permeate the membrane at different rates. The permeability, $\mathrm{P}\left[\mathrm{cm}^{3}(\mathrm{STP}) \cdot \mathrm{cm} / \mathrm{cm}^{3} \cdot \mathrm{s} \cdot \mathrm{cmHg}\right]$ is a measure of the permeation rate of a component through a membrane material. Permeability is defined as the rate at which that gas moves through a membrane of standard thickness $(1 \mathrm{~cm})$ under a standard driving 
force (a pressure difference of $1 \mathrm{cmHg}$ ). It can be shown that permeability can be expressed as the product

$$
P=D \cdot k
$$

where $D$ is the diffusion coefficient of the gas in the membrane $\left[\mathrm{cm}^{2} / \mathrm{s}\right]$, which is a measure of the gas mobility, and $k$ is the Henry's law sorption coefficient $\left[\mathrm{cm}^{3}(\mathrm{STP}) / \mathrm{cm}^{3} \cdot \mathrm{cmHg}\right.$, which links the concentration of the gas in the membrane material to the pressure in the adjacent gas. A measure of the ability of a membrane to separate two gases is the selectivity, $\alpha$, defined as the ratio of the gas permeabilities. ${ }^{6,7}$

$$
\alpha=\frac{P_{1}}{P_{2}}=\frac{D_{1}}{D_{2}} \cdot \frac{k_{1}}{k_{2}}
$$

The intrinsic selectivity of a polymer material is established by measuring the permeabilities with pure gas or vapor samples, then calculating the ratio. The actual selectivity obtained in a real separation process is established by measuring the permeability with gas mixtures. In practice the actual mixed gas selectivity is usually significantly less than the intrinsic selectivity.

In glassy polymers, the membrane selectivity is determined principally by the ratio of the diffusion coefficients, $D_{I} / D_{2}$ in equation (2), which is heavily dependent on the ratio of the permeate molecular sizes. ${ }^{8-10,11}$ In rubbery materials, the membrane selectivity is determined principally by the ratio of the sorption coefficients, $k_{l} / k_{2}$, which reflects the ratio of the condensabilities of the two permeants. ${ }^{12}$ Methane is a larger molecule than nitrogen, but is also slightly more condensable. Because the effects of condensability and molecular size are opposed, membranes can be made with selectivities that range from slightly nitrogen-selective (diffusion coefficient controlled) to moderately methaneselective (solubility or condensability controlled).

Recently, ceramic membranes that permeate nitrogen over methane as a size-selective sieve have been developed. ${ }^{13}$ These membranes are interesting because they promise high nitrogen/methane selectivity; however, scale-up issues are significant.

In rubbery polymers, methane permeates faster than nitrogen. Low temperatures facilitate absorption of methane in the membrane phase, resulting in increased selectivity over nitrogen. Additionally, in the presence of heavier hydrocarbons, absorption of methane in the polymer phase is increased. 


\subsection{Key Issues}

The objective of the Phase I study was to determine the feasibility of making membranes with a methane/nitrogen membrane selectivity sufficient for an economically viable process. Two types of polymer material — rubbery and superglassy — appeared to have the potential of achieving the required selectivity of 3 to 5 if operated at low temperatures.

Rubbery polymers are good candidate materials because of the different way in which temperature affects the diffusion and sorption coefficient terms in equation (2). Diffusion coefficients decrease with decreasing temperature; sorption coefficients increase. Therefore, for permanent gases such as nitrogen, for which the diffusion coefficient dominates, the permeability decreases with decreasing temperature. For organic vapors, for which the sorption coefficient dominates, the permeability is expected to increase with increasing temperature. Because temperature affects the permeabilities of vapors and gases oppositely, selectivity should increase as temperature decreases. This effect is quite large for the heavier hydrocarbons, $\mathrm{C}_{4}$ and above, found in natural gas but our data on methane were limited. We expected a modest increase in methane/nitrogen selectivity from 2-3 to 3-5 on cooling from $25^{\circ} \mathrm{C}$ to $-40^{\circ} \mathrm{C}$ for rubbery polymers such as silicone rubber, poly(siloctylene-siloxane), and polyamide-polyether copolymers.

Superglassy polymers, such as poly(1-trimethylsilyl-1-propyne) [PTMSP] ${ }^{14,15}$ and poly(4-methyl-2pentyne) $[\mathrm{PMP}],{ }^{16}$ were considered for different reasons. Operation of conventional glassy polymer membranes at low temperatures would normally result in significantly reduced permeation due to decreased diffusion coefficients at low temperatures and generally lower selectivity. However, the unusually high free volume of superglassy polymers produces anomalous permeation properties ${ }^{17}$ For example, in the presence of $1 \%$ butane, the methane permeability is 20 times lower than the pure methane permeability. When the condensable butane vapor is removed, the methane permeability returns to its original value. The best explanation for these unusual permeation properties is that the polyacetylenes, because of their exceptionally high free volumes, have passed from being a polymer film with a distribution of transient free volume elements to an ultra-microporous membrane in which pore flow transport occurs. Apparently, when operated with nitrogen-contaminated natural gas the heavier components of the gas condense in the membrane pores. This blocks permeation of nitrogen but allows some permeation of methane because of its greater solubility in hydrocarbon liquids. Because the effect is caused by condensation of liquids in the membrane pores, it is also more noticeable at low temperatures.

One problem with PMP and PTMSP is collapse of the ultramicroporous structure, which results in lower permeabilities and reduced methane/nitrogen selectivities. In fact, this problem proved to be insoluble and led us to abandon further development of these materials for the application despite their exceptional properties. 


\section{PHASE I OBJECTIVES AND ACHIEVEMENTS}

The overall objective of the Phase I project was to develop high-performance membranes for the separation of nitrogen from natural gas, and to identify suitable process designs for this application.

The specific objectives of the Phase I program were to:

1. Evaluate the separation characteristics of the membrane materials in the temperature range $-30^{\circ} \mathrm{C}$ to $22^{\circ} \mathrm{C}$ and under a variety of feed conditions.

Three polymer materials, silicone rubber (rubbery), a polyamide-polyether copolymer, Pebax® 2533 (rubbery), and PTMSP (superglassy), were evaluated. The methane/nitrogen selectivity was measured at temperatures from 22 to $-30^{\circ} \mathrm{C}$. [In Phase II we also tested poly(propylene oxideallylglycidylether) Parel (rubbery) and PMP (superglassy).]

We concluded from the results of these tests that PTMSP and silicone rubber warranted further development in Phase II.

2. Refine the membrane process design and identify means of lowering the total energy consumption.

The original process design was analyzed in detail; the analysis revealed that the energy consumption depends on the permeate pressure. Raising the permeate pressure from atmospheric to 100 psia reduces the net energy consumption substantially, without increasing the required membrane area significantly. An economic analysis showed that the membrane process is competitive with alternative technologies provided a membrane selectivity of 3 to 5 can be maintained in modules and under field conditions.

3. Select, based on the performance calculations and contacts with potential users, the most appropriate applications on which to focus scale-up work in Phase II.

Our survey of potential users and industry experts confirmed that nitrogen separation from natural gas is an extremely important problem, and that development of a suitable low-cost technology is a priority need. Based on conversations with potential users, we prepared a series of process flow diagrams, in which membranes were combined with other technologies to maximize the overall efficiency of the separation. Designs for these combined processes, which are applicable over a wide range of feed nitrogen contents and flow rates, were further developed in Phase II.

\section{PHASE II OBJECTIVES AND ACHIEVEMENTS}

The overall objective of Phase II of the project was to scale up the membrane tests by making modules for evaluation, first using in-house test systems at MTR and later in a field demonstration. 
A further objective of Phase II was to determine the market needs and potential and to characterize the marketplace.

The specific objectives of Phase II were:

1. Prepare bench-scale modules and test in laboratory to determine flux and selectivity

We prepared bench-scale membrane modules from silicone rubber, PMP, and Parel. After characterizing these modules, silicone rubber was selected as the best material for scale up and evaluation in the field test unit.

2. Identify field test site and field test the selected membrane in a suitably modified system. Perform long-term tests.

In spite of contacting a large number of potential users, we were unable to find a field site that met the needs for demonstration of the process during the project period. To obtain data similar to that expected from field tests, we performed tests at MTR's facilities in which essentially identical field conditions were generated in terms of flow rate, pressure, and temperature. A limited parametric test program was performed to determine the separation performance under differing feed conditions. We also performed a continuous performance test lasting 120 hours.

3. Complete Technical and Economic Analysis. Discuss application with potential users and analyze competing technologies.

During the project we supplied 5 commercial proposals and more than 10 technical evaluations to actual customers who contacted us. The results of these evaluations are described in Section 6.2. We also contacted suppliers of competing technologies to better understand the market and the advantages and disadvantages of other technologies. The results of this evaluation are discussed in Section 6.1 of this report.

As a result of the work performed on the project four patent applications were prepared, all of which have been issued. Details of the patents are also given in Section 6.3 of this report.

\section{EXPERIMENTAL TECHNIQUES AND PROCEDURES}

\subsection{Selection of Polymers}

Three selective polymer membrane materials were evaluated in Phase II of this project: silicone rubber, PMP and Parel.

Silicone Rubber: Silicone rubber membranes were prepared by coating a solution of silicone rubber onto a polyetherimide (PEI) support layer. Two membrane thicknesses were used: $10-\mu \mathrm{m}$-thick 
membrane for the larger 4-inch module tested in the field test system, and 30- $\mu \mathrm{m}$-thick membrane for the smaller modules tested in the laboratory-scale system.

PMP: PMP is a superglassy polymer similar to PTMSP, which was tested in Phase I. Early in the Phase II project we determined that the PTMSP membrane was not stable; its performance rapidly degraded due to a steep decline in flux over time. Since PTMSP was the best material tested in Phase I, this motivated us to identify similar polymer materials that could show similar performance but improved stability. We identified PMP as one such material.

Parel: This rubbery material was also tried as an alternative to silicone rubber and Pebax 2533. Although initial results were interesting, we discovered during scale-up of the membrane manufacturing process that the material is no longer available from the supplier and had to abandon its use.

\subsection{Membrane/Film Preparation}

Composite membranes of the type shown in Figure 2 were prepared from all the membrane materials. MTR manufactures this type of membrane on a commercial scale with a selective layer thickness of only 0.5-3 $\mu \mathrm{m}$. In this project, we made membranes with thicknesses between 3.5 and $30 \mu \mathrm{m}$ depending on the material and the purpose.

Figure 2. Schematic diagram of an MTR composite membrane.

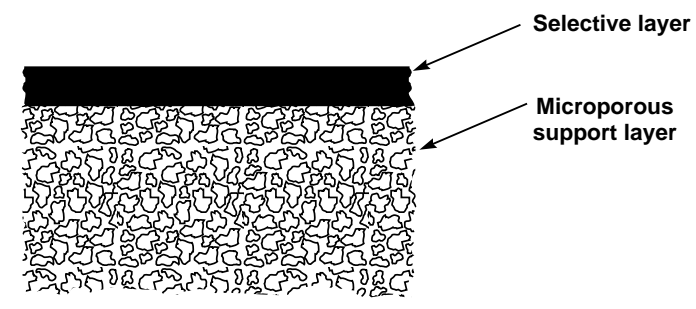

The microporous support layer shown in Figure 2 provides mechanical support and a smooth coating surface for the selective layer. The microporous substrate is formed by a casting process onto a backing paper. Its characteristics are determined by a number of factors including the nature of the backing paper, the solution viscosity, additives to the solution, and casting conditions. In a concurrent project, we successfully optimized the microporous support to make it suitable for high-pressure natural gas-related applications.

The selective layer, which performs the actual separation, must be thin and defect-free. Silicone rubber composite membranes were formed by coating a solution of the polymer in iso-octane onto a finely microporous support membrane. The resulting silicone rubber layer had a nominal thickness of about $30 \mu \mathrm{m}$. After coating, the membrane was dried at $60^{\circ} \mathrm{C}$ to crosslink the membrane. A thinner $10-\mu \mathrm{m}$ membrane was also manufactured for the 4-inch module tested in the field system.

PMP membranes were prepared on both polyvinylidene fluoride (PVDF) and polyetherimide (PEI) supports. Multiple coating steps were required to achieve a thick enough membrane for the tests; the 
nominal thicknesses of the PMP layers were $20-30 \mu \mathrm{m}$. The Parel membrane was prepared on a PEI support.

\subsection{Module Preparation}

The membranes were fabricated into spiral-wound modules of the type illustrated schematically in Figure 3. Feed gas enters the module and flows between the membrane leaves. The permeate fraction spirals inward to a central collection pipe. The remainder of the feed flows across the membrane surface and exits as the residue. To meet capacity and separation requirements of specific applications, membrane modules may be connected in a serial or parallel flow arrangement.

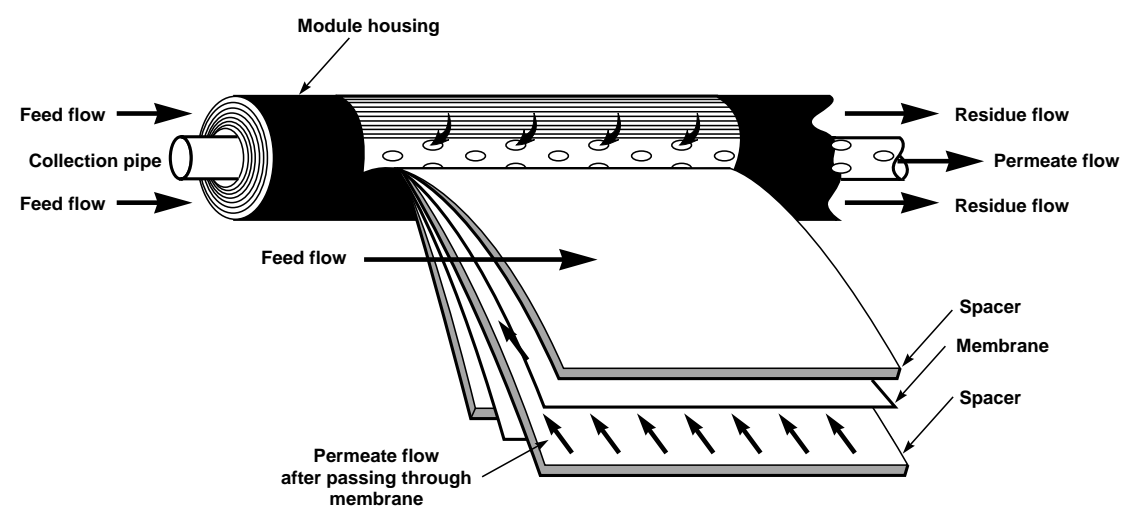

Figure 3. Schematic of a spiral-wound membrane module. The membrane area is MTR modules ranges from $0.2 \mathrm{~m}^{2}$ for laboratory modules to $5-20 \mathrm{~m}^{2}$ for commercial-sized modules.

The modules were prepared using the winding apparatus shown schematically in Figure 4. The membrane is cut to size and folded around the spacer material. The membrane envelope is then moved to the wind-up machine. The permeate collection pipe is placed in the jaws of a motor clutch, and the permeate spacer material is glued to the pipe. During the winding operation, the material is kept under a tension and the membrane envelope is glued along the edges and ends. Depending on the size of the spiral-wound module, a module may contain from one to sixteen membrane envelopes. A layer of reinforced tape is used to seal the module, after which a final protective fiberglass coating is applied. For operation, the module is placed in a steel pressure vessel.

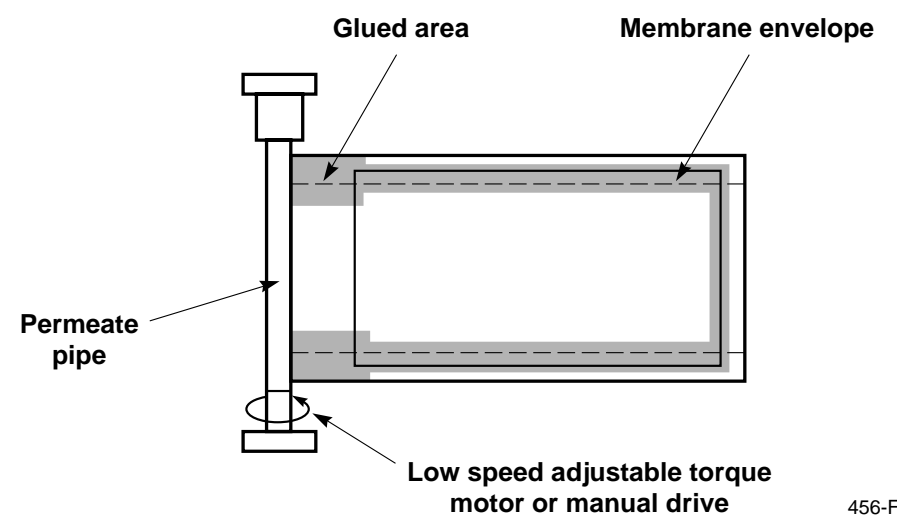

Figure 4. Schematic diagram of module winding apparatus. 


\subsection{Laboratory Module Tests}

Bench-scale modules were tested in the high-pressure test system shown in Figure 5. This system operates in total recycle mode and is equipped with a two-stage, 7.5-hp diaphragm compressor that can deliver up to $11 \mathrm{scfm}$ gas flow at pressures up to 1,500 psig. The gas is introduced into a highpressure vessel containing the module. The pressure of the residue gas is reduced and the gas mixed with the permeate gas before being recompressed by a small diaphragm compressor to about $30 \mathrm{psig}$. This combined stream forms the feed gas to the larger compressor. In this system, both residue and permeate streams are recycled and no gas loss occurs. The test system has an on-line GC sampling loop so that feed, residue, and permeate streams can be sampled continuously. The gas chromatograph is a $\mathrm{P} 200 \mathrm{H}$ portable TCD detector GC build by MTI (Fremont, CA); this GC can give a complete natural gas analysis $\left(\mathrm{C}_{1}\right.$ to $\left.\mathrm{C}_{20}\right)$ within two minutes. The test system is also equipped with inlet ports that allow injection of various heavier hydrocarbons into the flow loop.

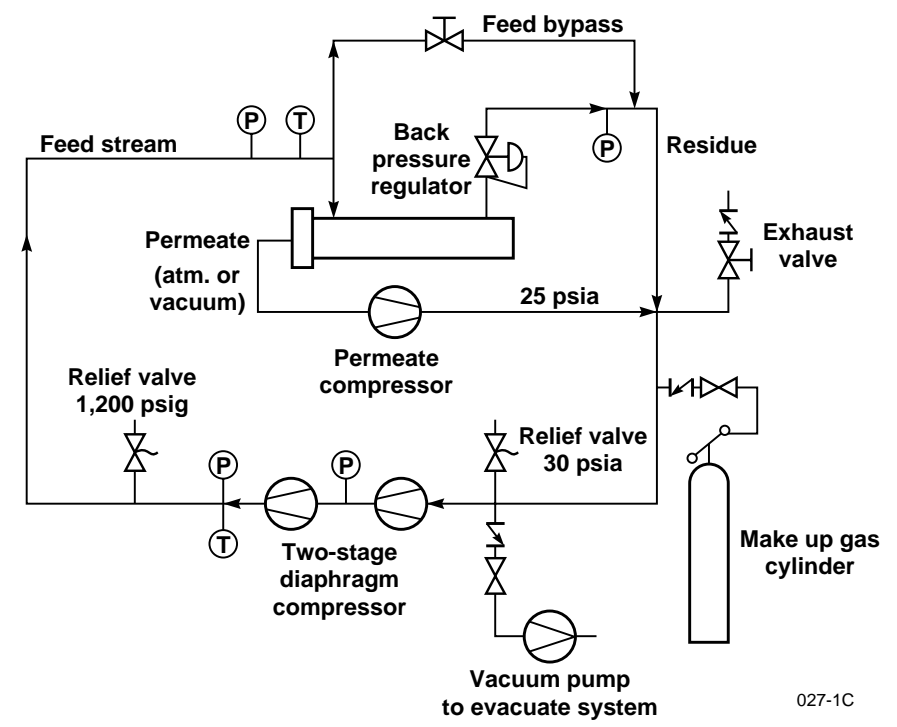

Figure 5. Flow diagram of the bench-scale test apparatus for determining module performance. The maximum feed pressure is $1,500 \mathrm{psig}$, and the maximum feed flow rate is $11 \mathrm{scfm}$.

\subsection{Field Test System}

The field test system was made by modifying an existing system built under a different project. Changes in the system were extensive, but even so considerable savings were made by reusing components. Figure 6 shows a simplified flow schematic of the unit. The system contains two filter separators, one for particulate matter and the other for condensate and natural gas liquids. The filtered gas then enters a set of three Pebax 2533 modules (3-inch diameter), which dehumidify the gas stream. The dried gas enters a bank of three heat exchangers which pre-cool the stream; any condensed liquids are separated in a filter before the gas enters the membrane unit. The methaneenriched gas is removed as a low-pressure permeate, and the non-permeate nitrogen-enriched gas is 
removed as a residue gas. Both the permeate and residue gases from the membrane system are 20$30^{\circ} \mathrm{C}$ colder than the inlet gas because of Joule-Thompson expansion that occurs as the high-pressure feed gas permeates the membrane. In addition, the high-pressure, nitrogen-enriched residue gas is expanded through a Joule-Thompson valve to achieve further cooling. These two gas streams are used in the heat exchangers to cool the incoming feed stream. Our calculations showed that the temperature of the test module could be lowered to -20 to $-40^{\circ} \mathrm{C}$ by using the Joule-Thompson cooling, but because of heat losses in the system the lowest incoming temperature of the gas to the module was only -5 to $-10^{\circ} \mathrm{C}$.

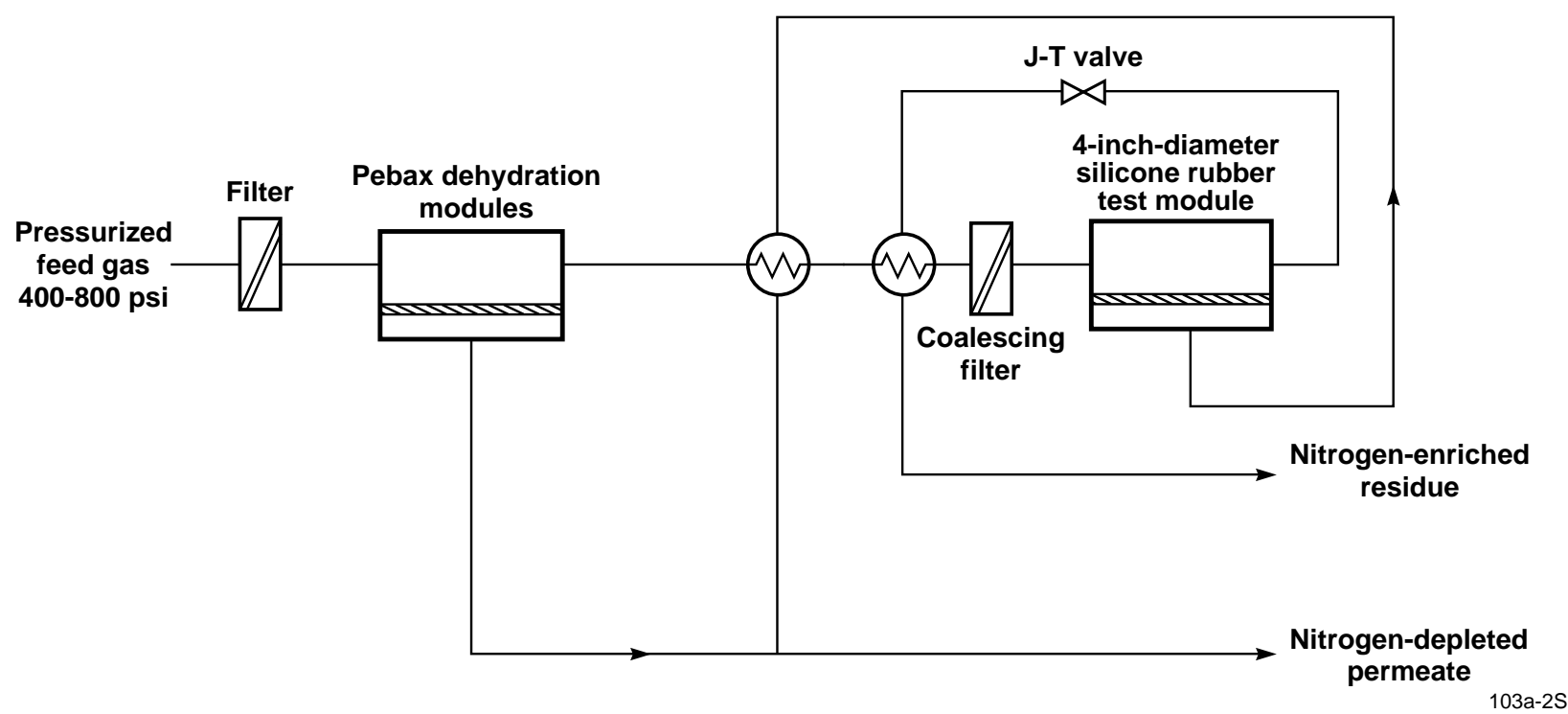

Figure 6. Simplified flow schematic of the membrane field test unit.

In the tests performed at MTR, the residue and permeate gases were combined and recycled to the suction of the two gas compressors. This allowed completely closed-loop operation during the test, eliminating the need for large volumes of natural gas. All three streams were monitored using sampling bags and the portable MTI gas chromatograph described earlier.

\section{EXPERIMENTAL RESULTS}

Permeation data were obtained with silicone rubber membranes incorporated in bench-scale and in commercial-scale modules and with PMP and Parel membranes incorporated in bench-scale modules. The PMP membrane modules showed good methane/nitrogen selectivities but the membrane fluxes were unstable, and selectivity decreased over operating time. The Parel modules had the best selectivities but the manufacturer of this polymer discontinued production during the course of the project, and we were unable to find an equivalent material in the time available. For these reasons silicone rubber membranes were used in the pilot test system. The silicone rubber data are described in detail below, but only the highlights of the PMP and Parel membrane data are given. 


\subsection{Silicone Rubber Membrane Modules}

The methane/nitrogen selectivities calculated from the measured permeation data for membrane stamps, small bench-scale modules (2 1/2-inch diameter) and larger (4-inch diameter) commercialscale modules are shown in Figure 7 as a function of feed pressure. The experiments were conducted under slightly different conditions of feed nitrogen content and feed temperature so the data in the figure have been averaged to allow comparison. The trends in methane/nitrogen are all virtually linear, so the averaging technique yields good results for comparative purposes.

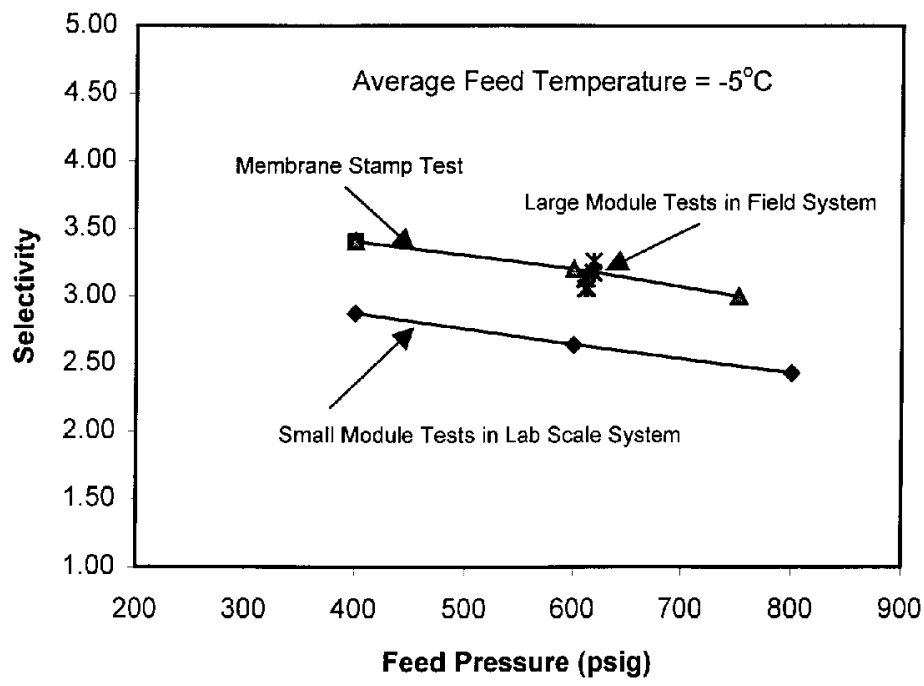

Figure 7. Comparison of methane/nitrogen selectivity for silicone rubber membrane stamps, small modules tested in the laboratory-scale system and a large 4-inch module tested in the field test system.

This figure shows the following noteworthy trends. First, selectivities measured for the small modules were lower than those obtained for membrane stamps and for the larger module. These lower selectivities were due to bypass of the feed in the small module tests at low temperatures. This bypass was caused by differing degrees of contraction of the glues and metallic components of the module on cooling, which opened up a small gap at the membrane seal cap carrier. This allowed a small portion of the feed gas to bypass the module unseparated. Bypass of the feed gas in larger modules is less noticeable because the amount of bypass gas is a much smaller fraction of the gas being separated by the membrane.

Second, the commercial-scale 4-inch module tested in the field system shows a membrane separation performance essentially identical to that of membrane stamps. This result is expected for this type of separation because the intrinsic membrane selectivity is not very high, therefore no mass-transferlimiting effects, such as concentration polarization, are expected in modules. 
Third, in general, the data show that increasing the pressure reduces the membrane selectivity. Most of the tests conducted in the field unit were at 580-620 psig at the temperature conditions indicated in the plot. We expect a similar decrease in selectivity as pressure increases with the larger modules as well.

Details of the data collected in the small module tests are given in Table 2, and Table 3 shows the data obtained from the continuous tests performed with the larger module.

Table 2. Data Obtained from Tests in the Laboratory-Scale Unit Using a $2 \frac{1}{2} 2$-inch Module.

\begin{tabular}{||c|c|c|c|c||}
\hline \hline \multirow{2}{*}{$\begin{array}{c}\text { Feed Temperature } \\
\left({ }^{\circ} \mathrm{C}\right)\end{array}$} & $\begin{array}{c}\text { Feed Pressure } \\
(\mathrm{psia})\end{array}$ & \multicolumn{2}{|c|}{$\begin{array}{c}\text { Pressure-Normalized Flux } \\
\left(10^{-6} \mathrm{~cm}^{3}(\mathrm{STP}) / \mathrm{cm}^{2} \cdot \mathrm{s} \cdot \mathrm{cmHg}\right)\end{array}$} & \multirow{2}{*}{$\begin{array}{c}\text { Methane/Nitrogen } \\
\text { Selectivity }\end{array}$} \\
\cline { 3 - 4 } & & Nitrogen & Methane & \\
\hline & 400 & 7.5 & 19.1 & 2.55 \\
& 600 & 8.0 & 2.8 & 2.61 \\
& 800 & 7.6 & 19.4 & 2.55 \\
& 1000 & 7.5 & 18.7 & 2.49 \\
\hline & 400 & 7.5 & 21.6 & 2.87 \\
& 600 & 7.1 & 18.8 & 2.64 \\
& 800 & 7.7 & 18.7 & 2.43 \\
& 1000 & 6.7 & 17.5 & 2.61 \\
\hline & 400 & 7.3 & 22.1 & 3.05 \\
& 600 & 6.0 & 18.0 & 2.98 \\
\hline & 800 & 6.0 & 17.3 & 2.90 \\
\hline
\end{tabular}


Table 3. Data obtained from the Five-Day Continuous Testing in the Field Test Unit Using the 4-inch Membrane Module.

\begin{tabular}{|c|c|c|c|c|c|c|c|}
\hline Date/Time & $\begin{array}{c}\text { Feed Flow } \\
\text { Rate } \\
(\text { scfm })\end{array}$ & $\begin{array}{c}\text { Feed } \\
\text { Pressure } \\
\text { (psia) }\end{array}$ & $\begin{array}{c}\text { Feed } \\
\text { Temperature } \\
\left({ }^{\circ} \mathrm{C}\right)\end{array}$ & $\begin{array}{c}\text { Feed } \mathrm{N}_{2} \\
\text { Content } \\
(\mathrm{mol} \%)\end{array}$ & $\begin{array}{c}\text { Pressure- } \\
\text { Normalized } \\
\text { Flux* } \\
\text { Nitrogen }\end{array}$ & $\begin{array}{c}\text { Pressure- } \\
\text { Normalized } \\
\text { Flux }^{*} \\
\text { Methane }\end{array}$ & $\begin{array}{c}\text { Selectivity } \\
\text { Methane/ } \\
\text { Nitrogen }\end{array}$ \\
\hline 10/18/99 12:00 PM & 22.2 & 631 & 11.9 & 5.46 & 23.1 & 66.5 & 2.88 \\
\hline 10/18/99 4:00 PM & 23.7 & 625 & 1.2 & 5.57 & 18.6 & 61.3 & 3.30 \\
\hline 10/18/99 8:00 PM & 23.7 & 597 & -1.9 & 5.73 & 18.5 & 58.9 & 3.18 \\
\hline 10/18/99 11:00 PM & 23.7 & 602 & -3 & 5.7 & 17.9 & 59.6 & 3.33 \\
\hline 10/19/99 3:00 AM & 22.9 & 601 & -3 & 5.72 & 17.9 & 59.7 & 3.34 \\
\hline 10/19/99 7:00 AM & 23.7 & 599 & -3.5 & 5.69 & 18.1 & 59.9 & 3.31 \\
\hline 10/19/99 11:00 AM & 23.9 & 620 & -6.1 & 5.65 & 16.9 & 58.3 & 3.45 \\
\hline 10/19/99 3:00 PM & 22.3 & 589 & -6.2 & 5.57 & 17.2 & 56.9 & 3.30 \\
\hline 10/19/99 7:00 PM & 22.9 & 610 & -6 & 5.67 & 16.5 & 56.2 & 3.42 \\
\hline 10/19/99 11:00 PM & 23.7 & 614 & -5.2 & 5.55 & 16.4 & 56.6 & 3.46 \\
\hline 10/20/99 3:00 AM & 22.7 & 607 & -5.5 & 6 & 17.9 & 55.8 & 3.12 \\
\hline 10/20/99 7:00 AM & 22.7 & 612 & -5.5 & 6.76 & 16.6 & 55.6 & 3.35 \\
\hline 10/20/99 11:00 AM & 23.9 & 618 & -7.1 & 7.61 & 16.5 & 55.3 & 3.35 \\
\hline 10/20/99 3:05 PM & 23.7 & 617 & -6.8 & 8.12 & 16.8 & 54.7 & 3.26 \\
\hline 10/20/99 7:00 PM & 23.4 & 622 & -6 & 8.64 & 16.4 & 53.5 & 3.26 \\
\hline 10/20/99 11:25 PM & 23.6 & 618 & -5.4 & 9.04 & 17 & 55.4 & 3.26 \\
\hline 10/21/99 3:00 AM & 24.1 & 617 & -5.5 & 9.31 & 17.2 & 54.6 & 3.17 \\
\hline 10/21/99 7:00 AM & 23.8 & 610 & -6 & 9.63 & 17.6 & 55.0 & 3.13 \\
\hline 10/21/99 11:00 AM & 24.1 & 618 & -6.2 & 10.1 & 17.2 & 54.5 & 3.17 \\
\hline 10/21/99 3:00 PM & 23.8 & 612 & -6 & 10.33 & 17.4 & 54.4 & 3.13 \\
\hline 10/21/99 7:00 PM & 24.1 & 612 & -5.5 & 10.5 & 17.9 & 54.8 & 3.06 \\
\hline 10/21/99 11:00 PM & 24.1 & 611 & -5 & 10.74 & 18.2 & 55.6 & 3.05 \\
\hline 10/22/99 3:15 AM & 24.1 & 615 & -5 & 10.88 & 18.4 & 55.1 & 2.99 \\
\hline 10/22/99 7:00 AM & 23.7 & 607 & -5.5 & 11.06 & 18.1 & 55.6 & 3.08 \\
\hline 10/22/99 11:00 AM & 23.0 & 607 & -6 & 11.2 & 17.9 & 54.7 & 3.06 \\
\hline 10/22/99 3:00 PM & 23.0 & 607 & -6 & 11.3 & 17.7 & 54.7 & 3.09 \\
\hline 10/22/99 7:00 PM & 23.0 & 600 & -6 & 11.3 & 17.9 & 55.6 & 3.11 \\
\hline 10/22/99 11:00 PM & 22.9 & 610 & -6 & 11.3 & 17.6 & 54.9 & 3.12 \\
\hline 10/23/99 2:00 AM & 23.4 & 628 & -5.9 & 16.25 & 17.8 & 53.4 & 3.00 \\
\hline 10/23/99 3:00 AM & 23.6 & 617 & -5.8 & 16.37 & 18.3 & 54.0 & 2.95 \\
\hline 10/23/99 5:00 AM & 24.8 & 630 & -5.3 & 20.97 & 18.3 & 52.0 & 2.84 \\
\hline 10/23/99 7:20 AM & 24.8 & 611 & -4.4 & 20.8 & 19.1 & 53.3 & 2.79 \\
\hline
\end{tabular}


${ }^{*} 10^{-6} \mathrm{~cm}^{3}(\mathrm{STP}) / \mathrm{cm}^{2} \cdot \mathrm{s} \cdot \mathrm{cmHg}$

The data given in Table 3 are shown graphically in Figures 8-10, which are plots of the feed flow rate, pressure, and temperature, respectively, as a function of time. The feed flow rate into the membrane system was maintained between 20 and $24 \mathrm{scfm}$ throughout the tests, essentially the maximum flow capacity of the two-compressor system that was used. The feed pressure was maintained between 590 and 620 psia. The feed temperatures decreased during the first few hours of the test as the system gradually cooled down. At steady state the temperature of the feed gas to the module was between -6 and $-5^{\circ} \mathrm{C}$. This temperature was substantially higher then expected from our calculations, indicating that either the gas-gas heat exchangers used were not large enough or that heat ingress into the system was substantial.

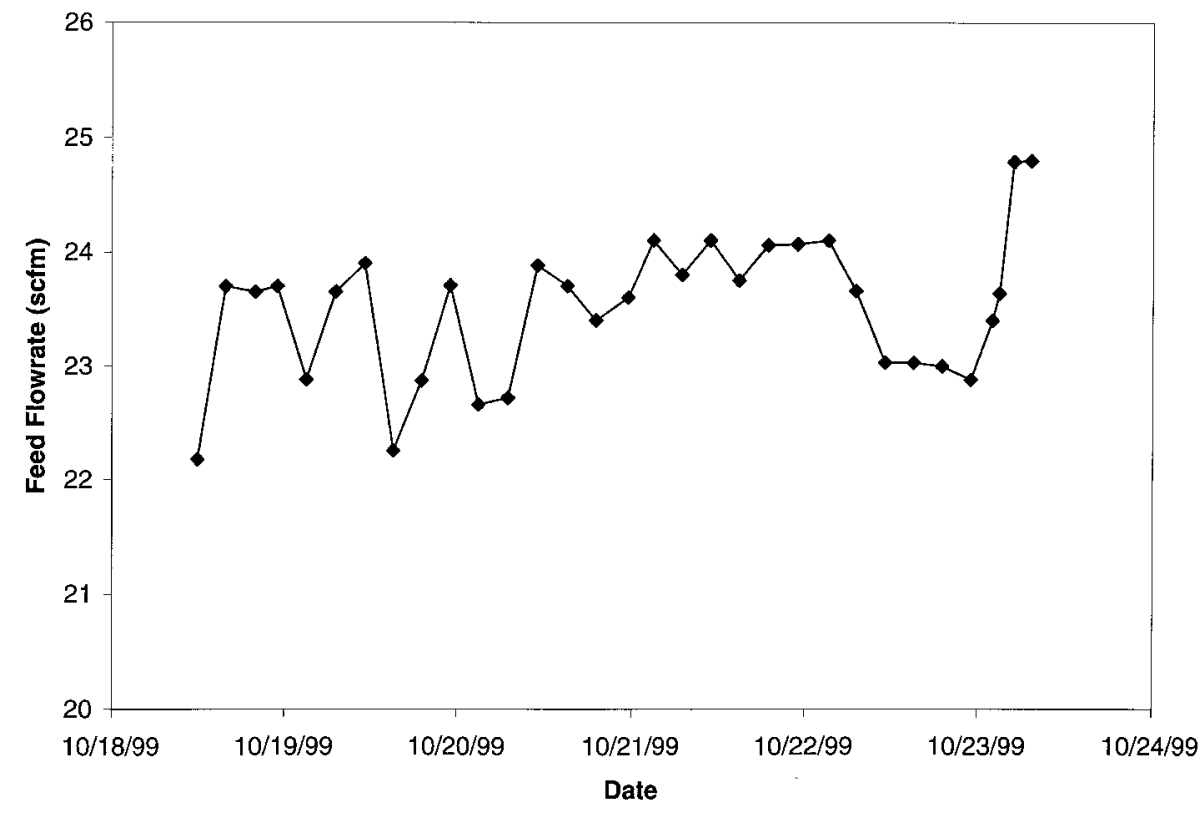

Figure 8. Feed flow rate as a function of time for the five-day test on the 4-inch silicone rubber module. 


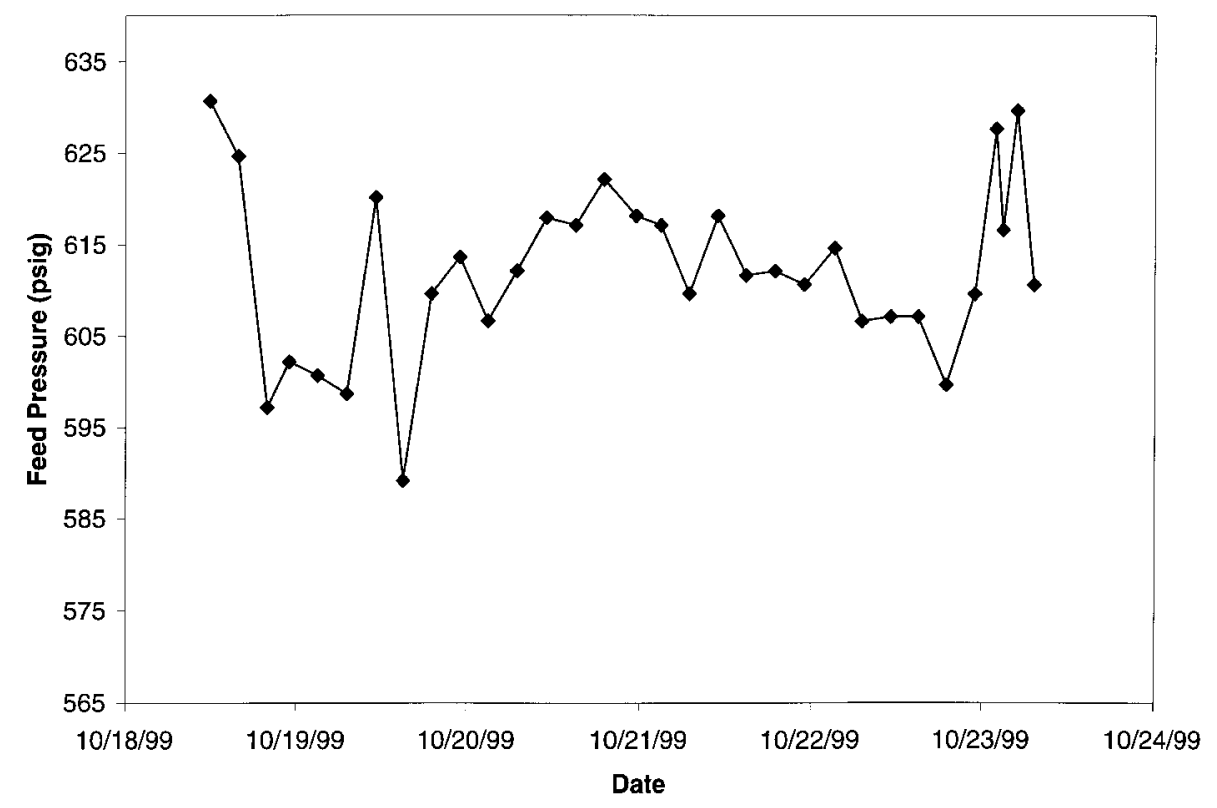

Figure 9. Feed pressure as a function of time for the five-day test on the 4-inch silicone rubber module.

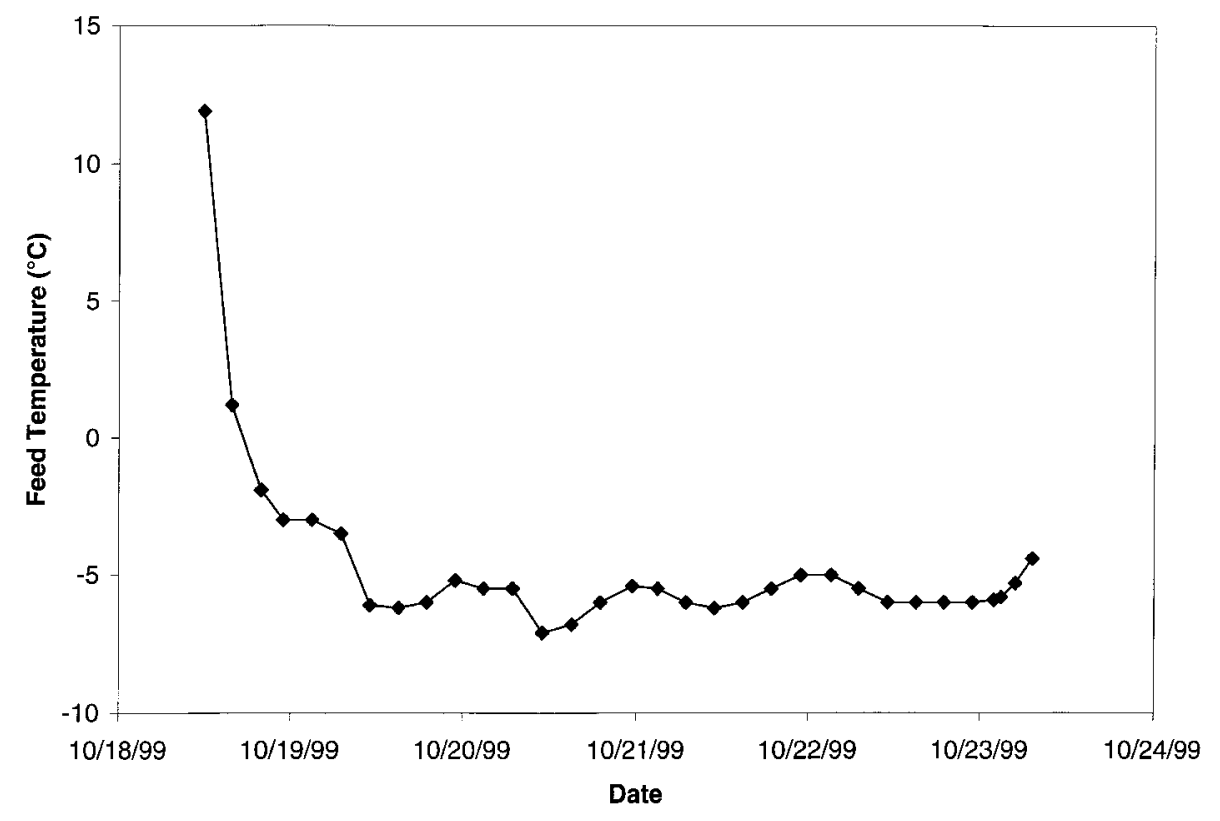

Figure 10. Feed temperature as a function of time for the five-day test on the 4-inch silicone rubber module. 
Figure 11 shows the feed, residue and permeate nitrogen content as a function of time. During the tests the nitrogen content in the system increased gradually as we added gas to compensate for losses from a gas cylinder containing a higher nitrogen content. The figure shows that the residue and permeate nitrogen content tracks that in the feed. For up to about $10 \%$ nitrogen in the feed, the permeate/product nitrogen content was below $4 \mathrm{~mol} \%$, meeting pipeline specification. During the last 12 hours we added pure nitrogen to rapidly increase the nitrogen feed content; this also increased the nitrogen content of the permeate stream. At $15 \%$ nitrogen in the feed, the permeate nitrogen content rose to about $6.5 \%$

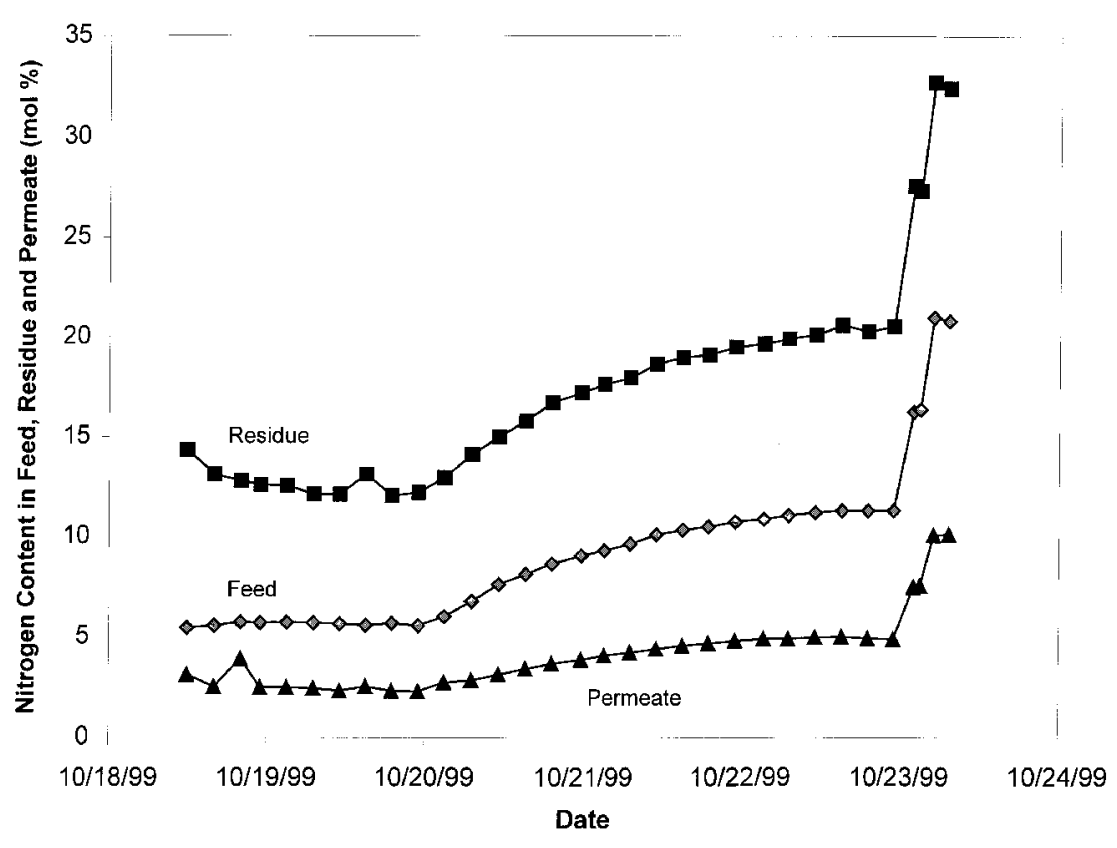

Figure 11. Feed, residue and permeate nitrogen content as a function of time during the long-term silicone rubber module test.

The methane and nitrogen pressure-normalized fluxes are shown as a function of time in Figure 12. As the nitrogen content increases, the methane flux decreases slightly while the nitrogen pressurenormalized flux remains essentially unchanged. During the 5 days of continuous testing we did not see any significant change in the nitrogen pressure-normalized flux. This indicates that at $-5^{\circ} \mathrm{C}$ to $25^{\circ} \mathrm{C}$ the membrane is stable in this gas mixture. 


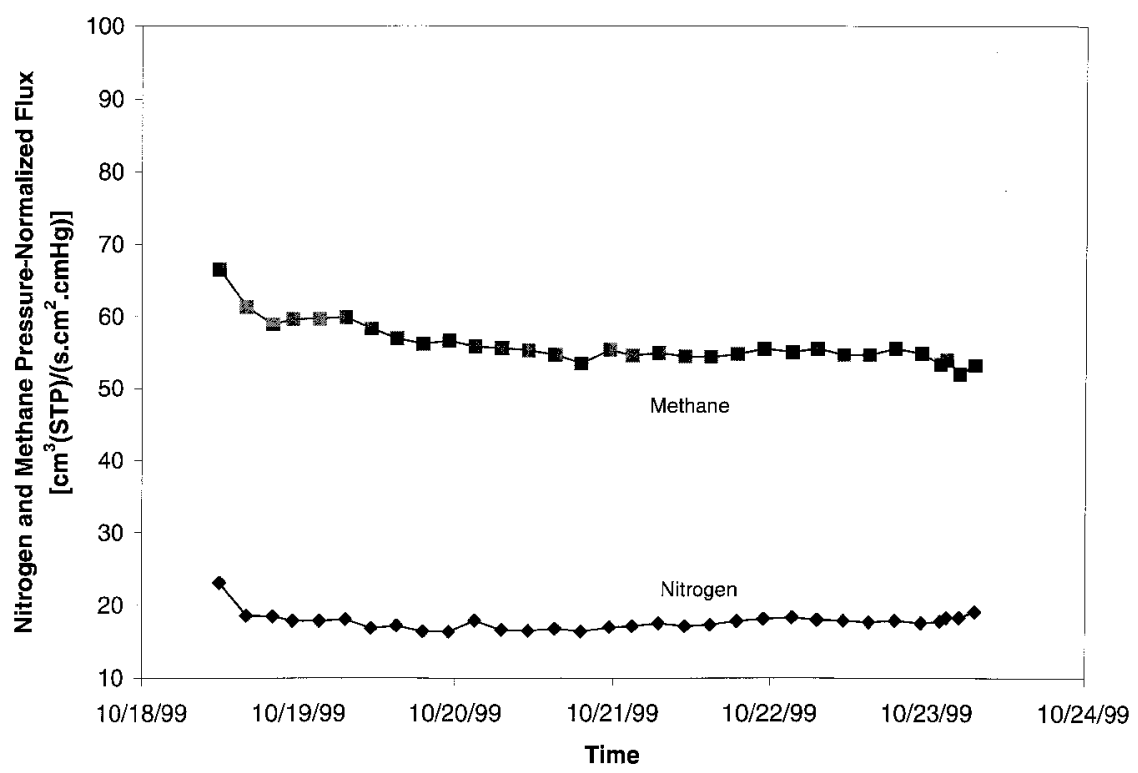

Figure 12. Pressure-normalized fluxes of methane and nitrogen as a function of time during the longterm silicone rubber module test.

Figure 13 shows the methane/nitrogen selectivity of the module as a function of time. As the feed nitrogen content increases, the module selectivity slowly decreases. At a feed gas nitrogen content of $5-10 \%$, the average methane/nitrogen selectivity is about 3.3. This number was used in our basecase analysis to determine the economics of the process.

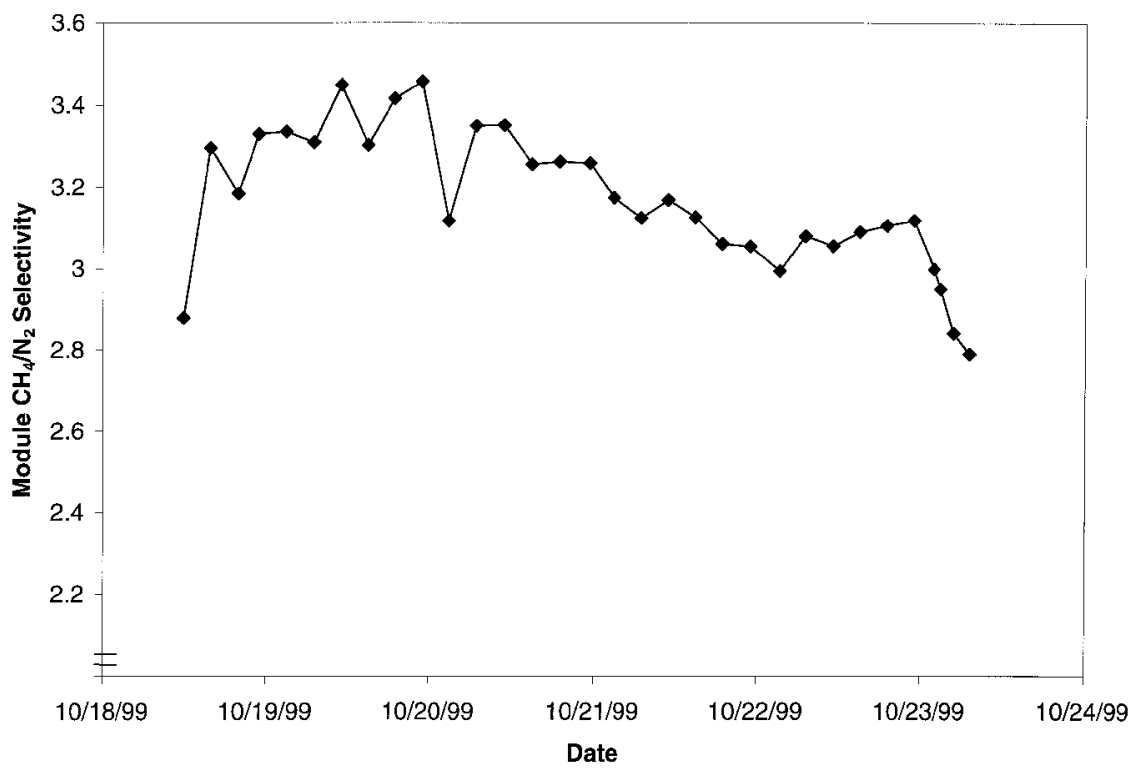

Figure 13. Methane/nitrogen selectivity as a function of time during the long-term silicone rubber module test. 


\subsection{PMP Membrane Module}

As described in Section 2, we initially evaluated membranes with a selective layer of PTMSP, a superglassy polymer, for this separation. However, long-term tests with membrane modules showed that the PTMSP membrane is not stable, resulting in a rapid decline in the permeation flux and selectivity if the operating conditions are not continuously and carefully monitored. This would not be practical in real applications, therefore we concluded that the PTMSP membrane is not a suitable candidate. However, because PTMSP membranes showed the best separation in Phase I, we investigated an alternative superglassy polymer, PMP, to determine if the excellent separation properties of this type of polymer could be combined with improved stability of the membrane.

However, the PMP membrane was also found to be unstable, even though it retained its separation properties longer than the PTMSP membrane. The results shown in Table 4 were obtained at various times, during which the module was undergoing changes. Therefore, some of the data have scatter that would typically not be observed in a membrane that was not undergoing changes in permeation properties during an experimental study. However, the most important data are shown in the table. Figure 14 shows a plot of the measured methane/nitrogen selectivity of the module as a function of the feed pressure and temperature.

Table 4. PMP Module Permeation Data.

\begin{tabular}{||c|c|c|c|c|c|c|c|c|c||}
\hline \multirow{2}{*}{$\begin{array}{c}\text { Feed } \\
\begin{array}{c}\text { Temperature } \\
\left({ }^{\circ} \mathrm{C}\right)\end{array}\end{array}$} & \multirow{2}{*}{$\begin{array}{c}\text { Feed } \\
\text { Pressure }\end{array}$} & \multicolumn{2}{|c|}{$\begin{array}{c}\text { Pressure- } \\
\text { Normalized } \\
\text { Flux* }\end{array}$} & \multicolumn{2}{|c||}{ Selectivity } \\
\cline { 3 - 11 } & & $\mathrm{N}_{2}$ & $\mathrm{CH}_{4}$ & $\mathrm{C}_{1} / \mathrm{N}_{2}$ & $\mathrm{C}_{2} / \mathrm{C}_{1}$ & $\mathrm{C}_{3} / \mathrm{C}_{1}$ & $n-\mathrm{C}_{4} / \mathrm{C}_{1}$ & $n-\mathrm{C}_{6} / \mathrm{C}_{1}$ & $n-\mathrm{C}_{8} / \mathrm{C}_{1}$ \\
\hline \multirow{4}{*}{30} & 400 & 7.7 & 17.6 & 2.3 & 2.5 & 3.7 & 7.3 & 16.3 & 23.0 \\
& 600 & 11.6 & 25.7 & 2.2 & 2.3 & 3.3 & 5.9 & 10.1 & 12.7 \\
& 800 & 13.2 & 27.7 & 2.1 & 2.1 & 2.9 & 4.5 & 6.5 & 8.1 \\
& 1,000 & 10.0 & 23.0 & 2.2 & 2.0 & 2.7 & 4.2 & 6.4 & 7.2 \\
\hline & 400 & 7.4 & 19.5 & 2.6 & 3.1 & 4.9 & 7.5 & 7.3 & 10.1 \\
& 600 & 11.2 & 28.4 & 2.5 & 2.7 & 3.8 & 5.6 & 6.6 & 8.1 \\
& 800 & 11.2 & 26.7 & 2.4 & 2.4 & 3.4 & 4.7 & 5.6 & 5.8 \\
& 1,000 & - & - & - & - & - & - & - & - \\
\hline \multirow{4}{*}{0} & 400 & 4.4 & 12.8 & 2.9 & 3.8 & 6.4 & 11.0 & 19.3 & - \\
& 600 & 7.2 & 19.2 & 2.7 & 2.7 & 3.7 & 5.0 & 5.1 & - \\
& 800 & 13.1 & 32.0 & 2.4 & 1.9 & 2.2 & 2.3 & 2.9 & - \\
& 1,000 & - & - & - & - & - & - & - & - \\
\hline
\end{tabular}

${ }^{*} 10^{-6} \mathrm{~cm}^{3}(\mathrm{STP}) / \mathrm{cm}^{2} \cdot \mathrm{s} \cdot \mathrm{cmHg}$ 


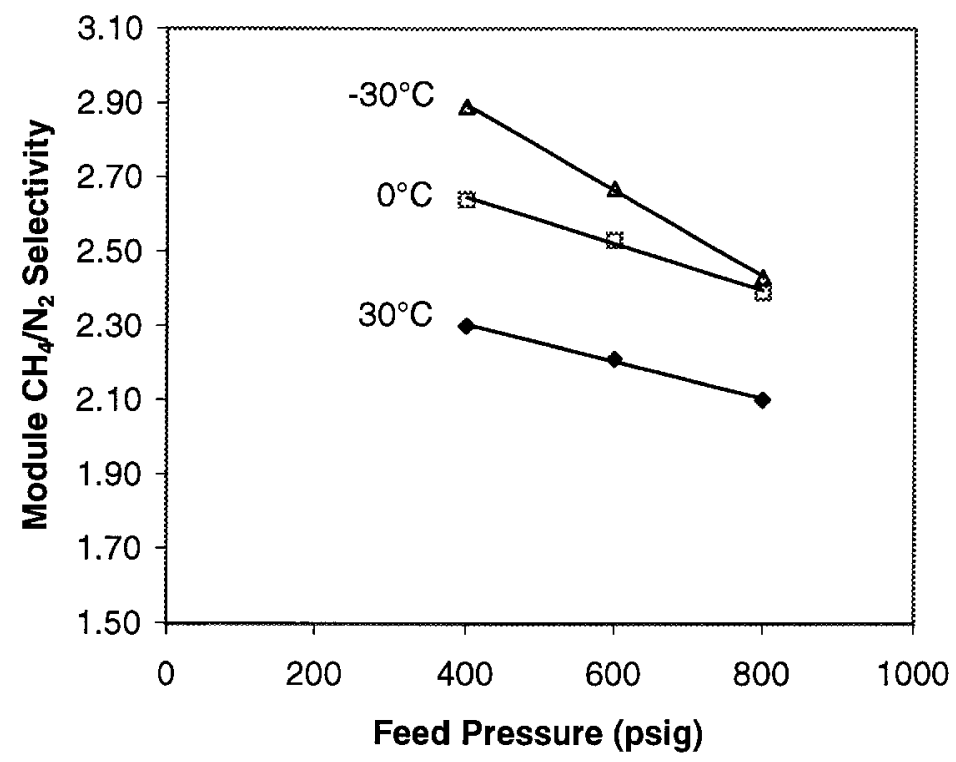

Figure 14. Effect of feed pressure and temperature on the PMP module methane/nitrogen selectivity.

One important feature of the plot in Figure 14 is the increase in the module selectivity with decreasing temperature. This is as expected, based on the results we obtained with PTMSP. Also, based on the earlier PTMSP data, we would postulate that this increase in selectivity as a function of temperature is due to a smaller decrease in the methane permeation flux compared to the nitrogen flux. This may be true for PMP also, but due to the scatter in the data it is not readily evident.

Figure 14 also shows that an increase in feed pressure at any given temperature results in a decrease in the methane/nitrogen selectivity. This behavior is observed for all feed components and can be attributed to a number of factors. The most likely are non-ideality effects in the gas phase at higher pressures and perhaps some concentration polarization effects. However, this behavior implies that the membrane separates gases less efficiently at higher pressures.

The PMP module selectivity is compared with that of a PTMSP film under similar pressure and temperature conditions in Figure 15. The data for PTMSP were obtained in Phase I of the project. Clearly, the PMP module selectivity is lower than the selectivity obtained with the PTMSP membrane in Phase I. Based on extrapolation of the PTMSP selectivity obtained in Phase I, we had expected a selectivity of more than 5 at lower temperatures. However, the PMP module data shown in Figure 15 , suggest that a selectivity of only about 3.0 would be obtained. Therefore, even without the stability issue, the membrane is not a good candidate for this application. 


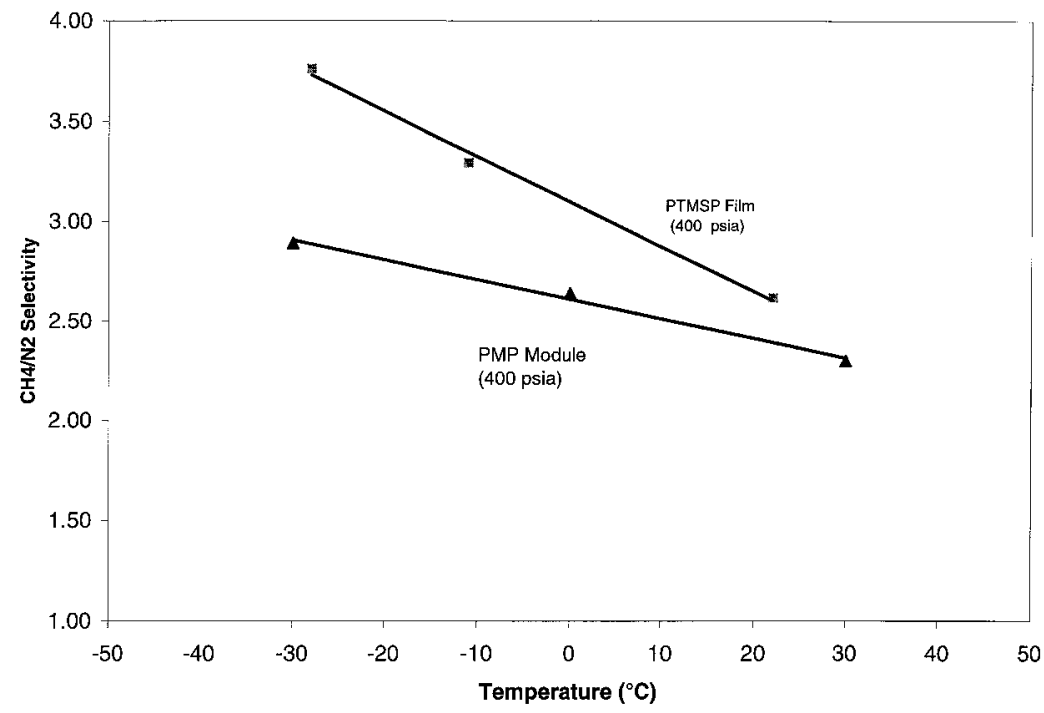

Figure 15. Comparison of the PMP module selectivity and PTMSP membrane selectivity.

\subsection{Parel Membrane Module}

The third material investigated was Parel, which is a rubbery polymer similar to Pebax 2533. The Pebax 2533 membrane has a pure gas methane/nitrogen selectivity of 4 at ambient temperatures and is potentially a good material for this separation. Parel was expected to be a better version of this material with the potential for even higher selectivities at lower temperatures. To investigate this possibility we performed a number of experiments with a Parel module. The most important results are summarized in Table 5 and shown graphically in Figure 16, a plot of methane/nitrogen selectivity as a function of feed temperature. 
Table 5. Summary of Parel Module Test Results.

\begin{tabular}{||c|c|c|c|c||}
\hline \multirow{2}{*}{$\begin{array}{c}\text { Feed Pressure } \\
(\mathrm{psia})\end{array}$} & $\begin{array}{c}\text { Feed Temperature } \\
\left({ }^{\circ} \mathrm{C}\right)\end{array}$ & \multicolumn{2}{|c|}{$\begin{array}{c}\text { Pressure-Normalized Flux } \\
\left(10^{-6} \mathrm{~cm}^{3}(\mathrm{STP}) / \mathrm{cm}^{2} \cdot \mathrm{s} \cdot \mathrm{cmHg}\right)\end{array}$} & $\begin{array}{c}\mathrm{C}_{4} / \mathrm{N}_{2} \\
\text { Selectivity }\end{array}$ \\
\cline { 2 - 4 } & & $\mathrm{N}_{2}$ & $\mathrm{CH}_{4}$ & \\
\hline \multirow{3}{*}{400} & 24 & 15.6 & 46.8 & 3.0 \\
& 0 & 9.5 & 31.6 & 3.3 \\
& -32 & 3.5 & 13.9 & 4.0 \\
\hline \multirow{3}{*}{600} & 25 & 16.4 & 46.6 & 2.8 \\
& 1 & 10.1 & 32.4 & 3.2 \\
& -30 & 5.4 & 20.8 & 3.9 \\
\hline \multirow{3}{*}{800} & 25 & 16.4 & 45.6 & 2.8 \\
& -1 & 10.3 & 31.9 & 3.1 \\
& -30 & 4.7 & 17.2 & 3.7 \\
& -30 & 4.2 & 14.6 & 3.5 \\
\hline \multirow{3}{*}{1000} & -30 & 3.2 & 11.1 & 3.4 \\
& 25 & 16.7 & 45.2 & 2.7 \\
& -1 & 11.1 & 32.9 & 3.0 \\
& -30 & 4.1 & 13.6 & 3.3 \\
\hline
\end{tabular}

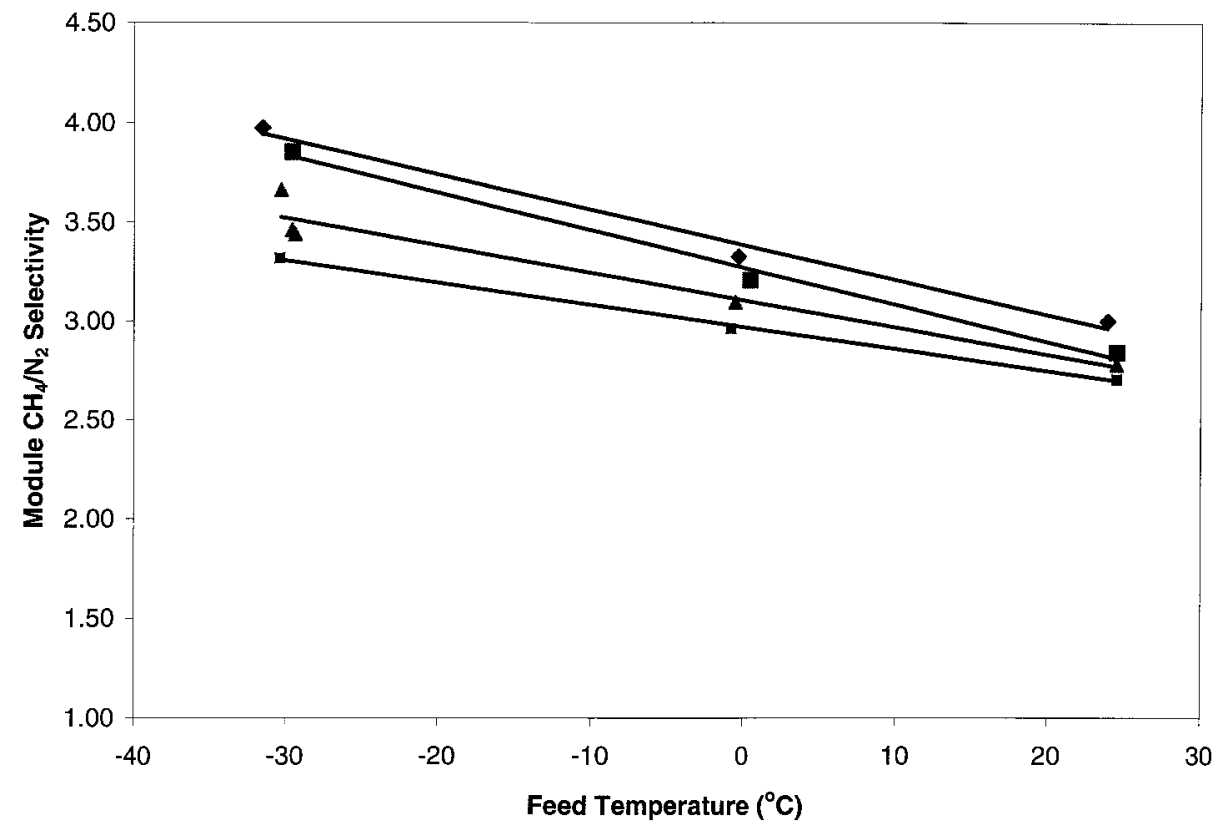

Figure 16. Methane/nitrogen selectivity as a function of feed temperature at feed pressures of 400, 600, 800 and 1,000 psia for the Parel module. Symbols: 400 psia; 600 psia; 800 psia; - 1,000 psia. 
The following interesting trends can be seen in Figure 16. The methane/nitrogen selectivity for this material ranges from about 4 at $-30^{\circ}$ to 2.7 at $20^{\circ} \mathrm{C}$. The effect of pressure is similar to that obtained in other membranes, with a decrease in the selectivity as the feed pressure increases. One additional interesting result for this Parel membrane is that the decrease in the selectivity at higher pressure is less pronounced than for silicone rubber and PMP.

Although Parel is a good candidate for this application, the supplier of the material has discontinued its manufacture; therefore, we cannot use it as a membrane. We will continue to investigate whether a similar material is available because we believe that the properties are very promising if they can be maintained under field conditions.

\subsection{Summary of Experimental Results}

A comparison of the module selectivity as a function of temperature for all the materials we investigated is given on a single plot in Figure 17. PTMSP film selectivity is also included.

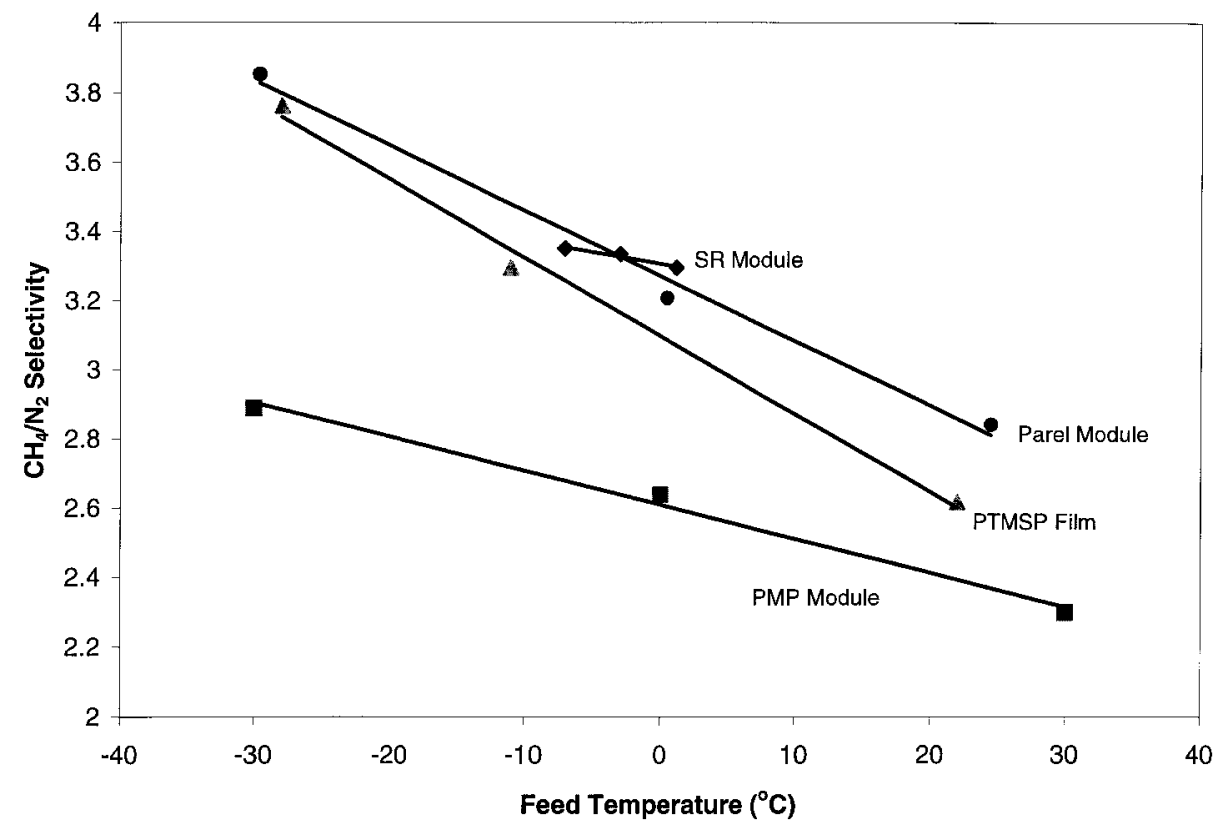

Figure 17. Comparison of methane/nitrogen selectivities for all the modules evaluated in the project.

The data indicate that the silicone rubber and Parel modules show the highest methane/nitrogen selectivity. However, because Parel is no longer available, we did most of the larger module continuous testing with a silicone rubber membrane module. The plot also indicates that the increase in selectivity at lower temperatures is greatest for the PTMSP membrane. However, the instability of the material precludes its use in commercial applications. PMP was expected to show permeation properties similar to those of PTMSP, but based on the data obtained we found that the 
methane/nitrogen selectivity of PMP is lower than that of PTMSP, and its stability is also questionable.

\section{TECHNICAL AND ECONOMIC ANALYSIS}

\subsection{Basis of Calculations}

\subsubsection{Base Case Feed Conditions and Design Variables.}

A series of preliminary calculations of various process designs were made, after which the two most promising designs were selected for detailed examination. These are a stand-alone membrane process (Section 6.1.2) and a combined membrane/cryogenic process (Section 6.1.3). Calculations were performed using ChemCad III (ChemStations, Houston, TX), which is a computer process simulation program that we have modified to include membrane operations. The economic evaluation was based on the operating conditions and feed gas compositions shown in Table 6.

Table 6. Operating Conditions and Feed Gas Compositions Used for ChemCad III Process Simulations.

\begin{tabular}{||c|c||}
\hline Parameter & Value \\
\hline Feed Temperature $\left({ }^{\circ} \mathrm{C}\right)$ & 25 \\
\hline Feed Pressure (psia) & 800 \\
\hline Permeate Pressure (psia) & 65 \\
\hline Required Product Pressure (psia) & 100 to 800 \\
\hline Total Std Gas Volume (MMscfd) & 4.7 \\
\hline Component (mol\%) & \\
Nitrogen & 8.0 \\
Methane & 82.85 \\
Ethane & 4.36 \\
Propane & 2.66 \\
N-Butane & 1.45 \\
N-Pentane & 0.48 \\
N-Hexane & 0.19 \\
\hline
\end{tabular}

The compositions shown in Table 6 are nominal. For the feed composition sensitivity study, the nitrogen content of the feed was varied between 8 and 14 mol\%, and the feed gas composition was normalized for each nitrogen content case. The product pressure was varied between 100 and 800 psia to determine the compressor size and cost. Two different membrane methane/nitrogen 
selectivities, 3.2 and 5, were also investigated to determine the sensitivity of processing costs to that variable.

\subsubsection{Process Design: Stand-Alone Membrane Process}

The process design used for this economic study of a stand-alone membrane process is shown in Figure 18. The feed gas enters the system and is cooled against returning streams from the membrane process in three consecutive heat exchangers. In the first heat exchanger (1), the membrane permeate is used to cool the feed gas; in the second heat exchanger (2), the membrane residue is used to cool the feed; and in the third heat exchanger (3), the collected condensed liquids are flashed to provide additional refrigeration to the feed gas. The substantial decrease in feed gas temperature due to this refrigeration results in significant condensation of liquids. The uncondensed portion of the feed gas is then processed in the membrane unit to produce a nitrogen-depleted permeate product stream and a nitrogen-enriched residue (nonpermeated) stream. These are the streams are used for the cooling process described above.

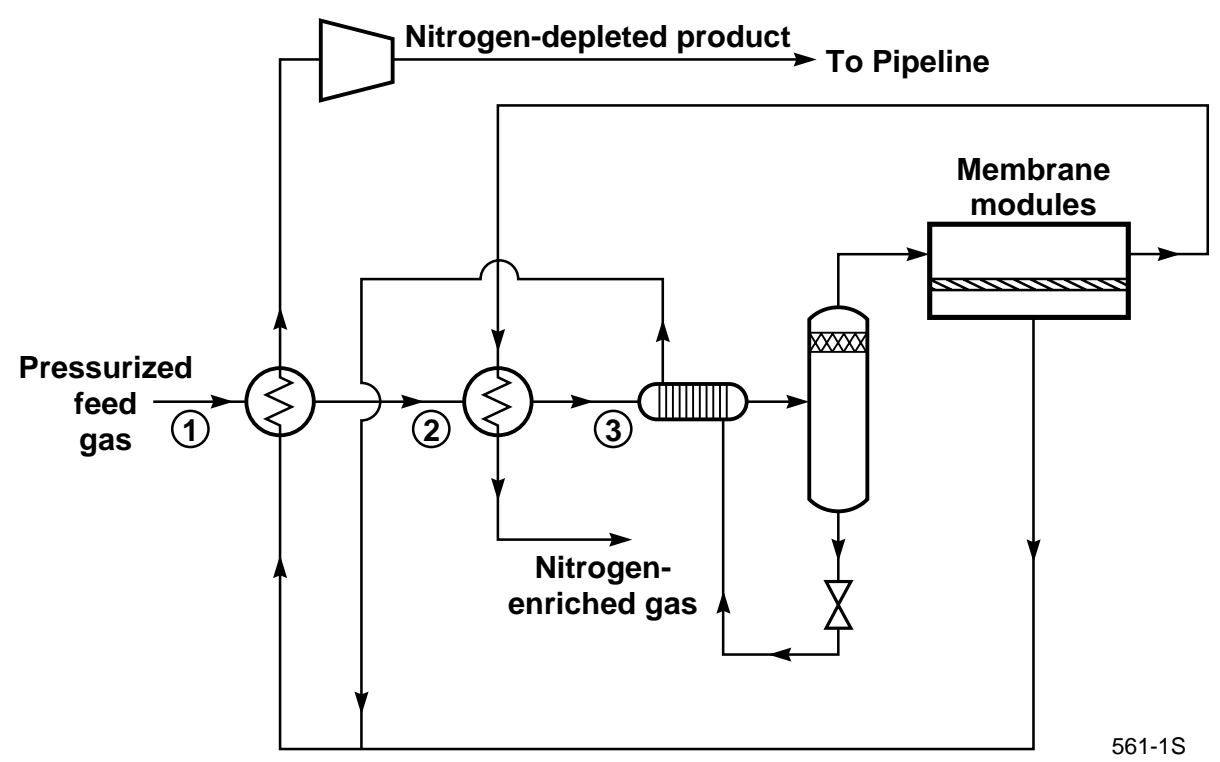

Figure 18. Process flow diagram for the stand-alone membrane process to separate nitrogen from methane.

\subsubsection{Process Design: Combined Membrane/Cryogenic Distillation Process}

Currently, the predominantly used technology to separate nitrogen from methane is cryogenic. ${ }^{3,18,19}$ Therefore, we performed an economic and technical evaluation of a combined membrane and cryogenic process to assess whether any synergies result from the combination. As shown in Figure 18, for the membrane process to be efficient, the operating temperature has to be lowered. Cryogenic processes also operate at very low temperatures. Our objective was to determine if combining the cold membrane process with a cryogenic process would result in significant cost reduction. 
A very simplified flow scheme of the combined membrane/cryogenic distillation process is shown in Figure 19. Heat integration is not shown. Feed gas enters the process from the left-hand side and passes across the membrane, which selectively permeates a fraction of the hydrocarbons in the feed. The remaining nitrogen-enriched gas is then expanded through a J-T valve and distilled in a cryogenic column. Nitrogen is removed from the top of the column and nitrogen-free hydrocarbon from the bottom. This hydrocarbon is mixed with the membrane permeate, recompressed, and sent to the pipeline. The fraction of the feed gas that permeates the membrane process bypasses the cryogenic unit, which becomes proportionately smaller and less costly. The costs of the combination membrane/cryogenic process are lower than those of either process used alone.

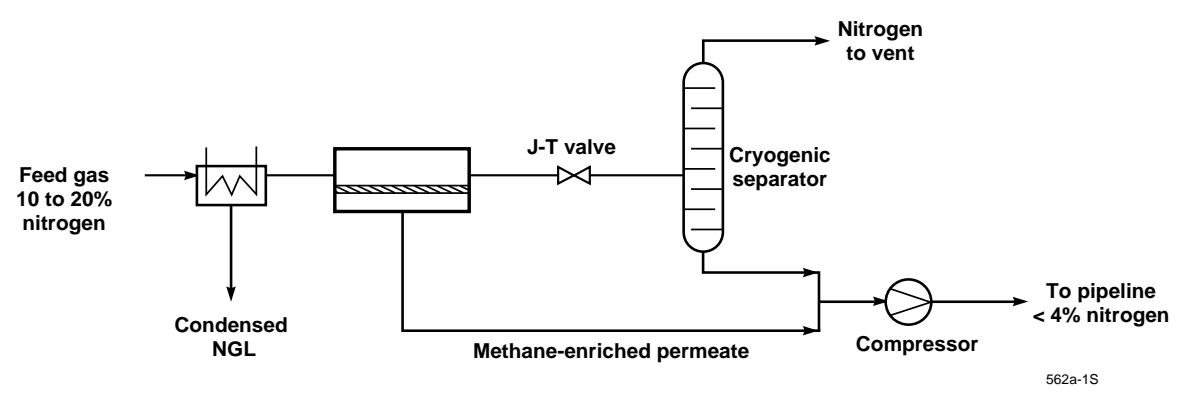

Figure 19. Simplified flow scheme of a combination membrane/cryogenic separation process.

Figure 20 shows a more complete schematic of this combined process. The front-end processing of the gas is similar to the stand-alone membrane process shown in Figure 18. The feed gas is dried by a molecular sieve bed (not shown) and cooled before it enters the membrane unit. In the simulation of the combined processes we varied the nitrogen content of the membrane permeate, and in effect increased it to 6-8 mol\%. This gas stream, when mixed and diluted with nitrogen-free gas from the cryogenic unit, meets the pipeline specification of $4 \%$ nitrogen. The residue gas from the membrane unit, still at pressure, then enters the cryogenic distillation process. Normally this would be a twocolumn process operating at different temperatures. Prior removal of any carbon dioxide in the feed gas is required to avoid freeze-outs. The temperature of the membrane residue gas is reduced within the cryogenic process by Joule-Thompson expansion or by a turbo-expander. The stream is condensed and then enters a cryogenic distillation column, where the nitrogen boils off as a top product while the methane is recovered as the bottoms. The recovered methane is then flashed to provide more refrigeration, and the flashed gas is mixed with the membrane permeate stream. The combined stream is sent to the product compressor for compression to the desired pressure. 


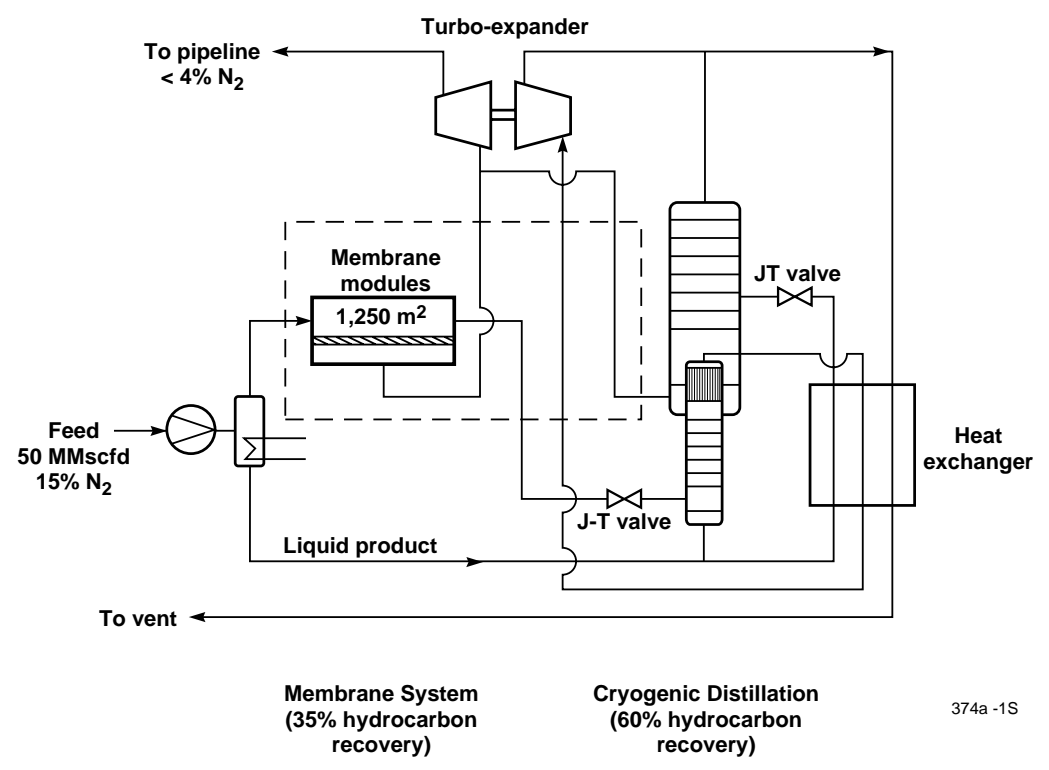

Figure 20. Flow schematic for combined membrane/cryogenic process.

Placing a membrane process in front of a cryogenic process reduces the flow of gas to the cryogenic system significantly. This reduces the size of the cryogenic plant and therefore its capital cost. Also, the combination plant provides very high methane recovery, which is a shortcoming of the stand-alone membrane process. Further synergies are described below.

\subsubsection{Assumptions for Cost Calculations}

The assumptions/properties given in Table 7 were used to perform the economic evaluations. These assumptions are based on our experience in quoting and building commercial systems and on data obtained from suppliers and operators. 
Table 7. Capital and Operating Costs of Combination Membrane/Cryogenic Process.

\begin{tabular}{||rr||}
\hline Capital Costs & \\
Membrane System (all inclusive) & $\$ 800 / \mathrm{m}^{2}$ \\
Compressor Skid & $\$ 16,000 \times(\mathrm{hp})^{0.4}$ \\
Cryogenic Plant & $7.3 \times 10^{6} \times(\text { Flow } / 15)^{0.6}$ \\
& \\
Annual Operating Costs & $20 \%$ Capital \\
Membrane Replacement Cost & $\$ 0.05 / \mathrm{kWh}$ \\
Power Cost & $4 \%$ Capital \\
Maintenance Cost & 1 Person $/ 8 \mathrm{hrs} / \$ 30 / \mathrm{h}$ \\
Labor & \\
& \\
Processing Cost (\$/Mscf) & $20 \%$ Capital \\
Capital recovery Cost (5 year) & As above \\
Operating Expenses & $\$ 2.0 / \mathrm{MMBtu}$ Lost \\
Shrinkage (Unrecovered Gas/Gas Loss)
\end{tabular}

\subsubsection{Economic Analysis of Base-Case Stand-Alone Membrane Process and Combined Membrane/Cryogenic Process}

To assess the technical and economic feasibility of the membrane process for the removal of nitrogen from methane, the following factors are important:

1. Membrane selectivity for methane over nitrogen

2. Required pipeline product pressure

3. Feed nitrogen content/product nitrogen content

The focus of the experimental program was to investigate both the membrane materials and the operating conditions necessary to increase the methane/nitrogen membrane selectivity. At a higher membrane selectivity, the recovery of methane is greater and the processing costs are lower. The product gas, depleted in nitrogen, is produced at a lower pressure than the feed to the membrane process (as is the case in all competing technologies); therefore, the required pressure for the final product gas is a very important cost factor. A higher required pipeline pressure consumes a greater amount of power, which impacts the compressor size and price. In many cases the cost of compression will dominate the overall processing cost. Therefore, higher product pressures increase processing costs.

The feed nitrogen content is also an important variable. Typically, pipeline specifications require the total amount of inerts in the product gas to be less than 3-5\% and require the product to meet a certain minimum heating value. If the gas is processed with a stand-alone membrane system, the higher the feed content of nitrogen, the more difficult it is to meet the required pipeline specifications. Typically, a higher nitrogen content results in decreased recovery of the product natural gas. Lower 
recovery directly impacts the processing costs and, therefore, the economics of the process. With current membranes having methane/nitrogen selectivities of 3-4, the membrane process can only obtain useful gas recoveries of greater than $60-80 \%$ for feed gas containing between 8 and 14 mol\% nitrogen. At higher nitrogen contents, a stand-alone membrane process cannot meet the required pipeline specifications at useful recoveries.

The impacts of membrane selectivity, product pressure and feed nitrogen content on processing costs are shown in Figure 21, which is a plot of the processing cost as a function of the required product discharge pressure. The plot shows the following cases: membrane methane/nitrogen selectivity of 3.25 and 5.0 and feed nitrogen content of $8 \mathrm{~mol} \%$ and $12 \mathrm{~mol} \%$. The most noteworthy aspects of the plot are described below.

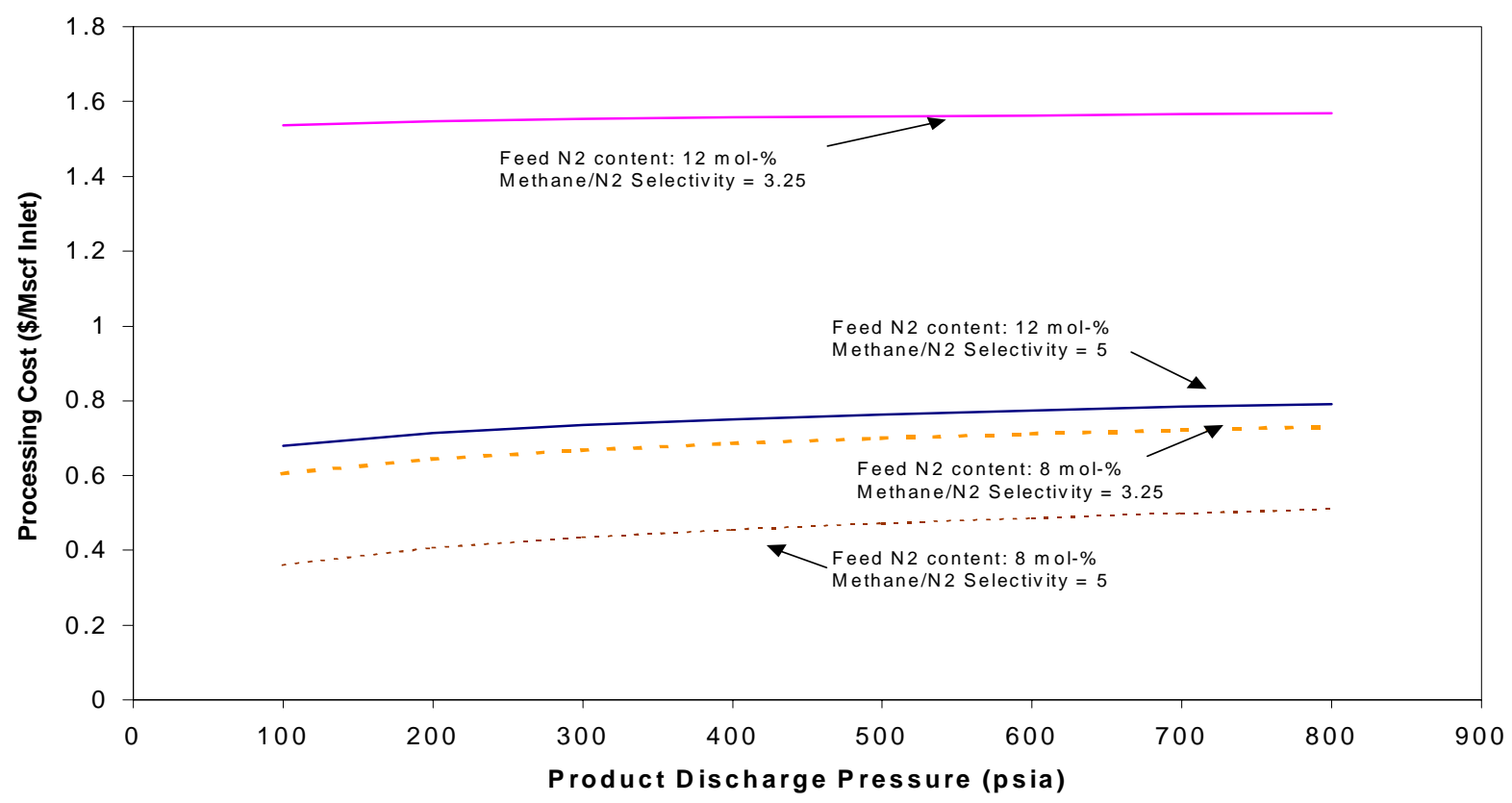

Figure 21. Impact of membrane selectivity, product discharge pressure, and feed gas nitrogen content on processing cost.

For a feed gas nitrogen content of $8 \mathrm{~mol} \%$, the approximate processing cost range is $\$ 0.6-0.7 / \mathrm{Mscf}$ for the currently available and tested membrane. The cost of a cryogenic process for this duty would be \$0.75-0.9/Mscf; therefore, the membrane process is competitive. However, the processing cost is somewhat high, which implies that the actual revenues to the producer will be low. If a membrane with a selectivity of 5 can be produced and demonstrated, the processing cost decreases to $\$ 0.35$ $0.45 / \mathrm{Mscf}$. In this range the process is significantly more competitive.

The situation changes significantly as the feed nitrogen content is increased to $12 \mathrm{~mol} \%$. With the currently demonstrated selectivity of about 3.2, the processing cost is more than $\$ 1.5 / \mathrm{Mscf}$, clearly not economically viable. Even with a membrane selectivity of 5, the processing cost is quite high, in the range of $\$ 0.7-0.8 / \mathrm{Mscf}$. This shows the significant effect of feed nitrogen concentration on the 
economics of the process. The reason for this behavior is illustrated by Figure 22, which shows the hydrocarbon recovery as a function of feed nitrogen content. As the feed nitrogen content increases, the recovery of hydrocarbons decreases very rapidly. The decline in recovery is most significant at the lower membrane selectivity of 3.25. This decreased recovery significantly increases the shrinkage cost (i.e. lost product), resulting in very high processing costs at high feed nitrogen contents.

Clearly, for the membrane process to succeed, the product recovery must to be increased while keeping the operating and capital costs within reasonable limits. One way of achieving higher recovery is to use a multi-stage membrane process, that is, to use two membrane stages with intermediate permeate recompression. However, this process requires two compressors, which increases the capital and operating costs. An alternative approach is a design that combines the membrane process with another suitable technology. Since most methane/nitrogen separation plants are cryogenic, we performed a detailed evaluation of a combined membrane/cryogenic process.

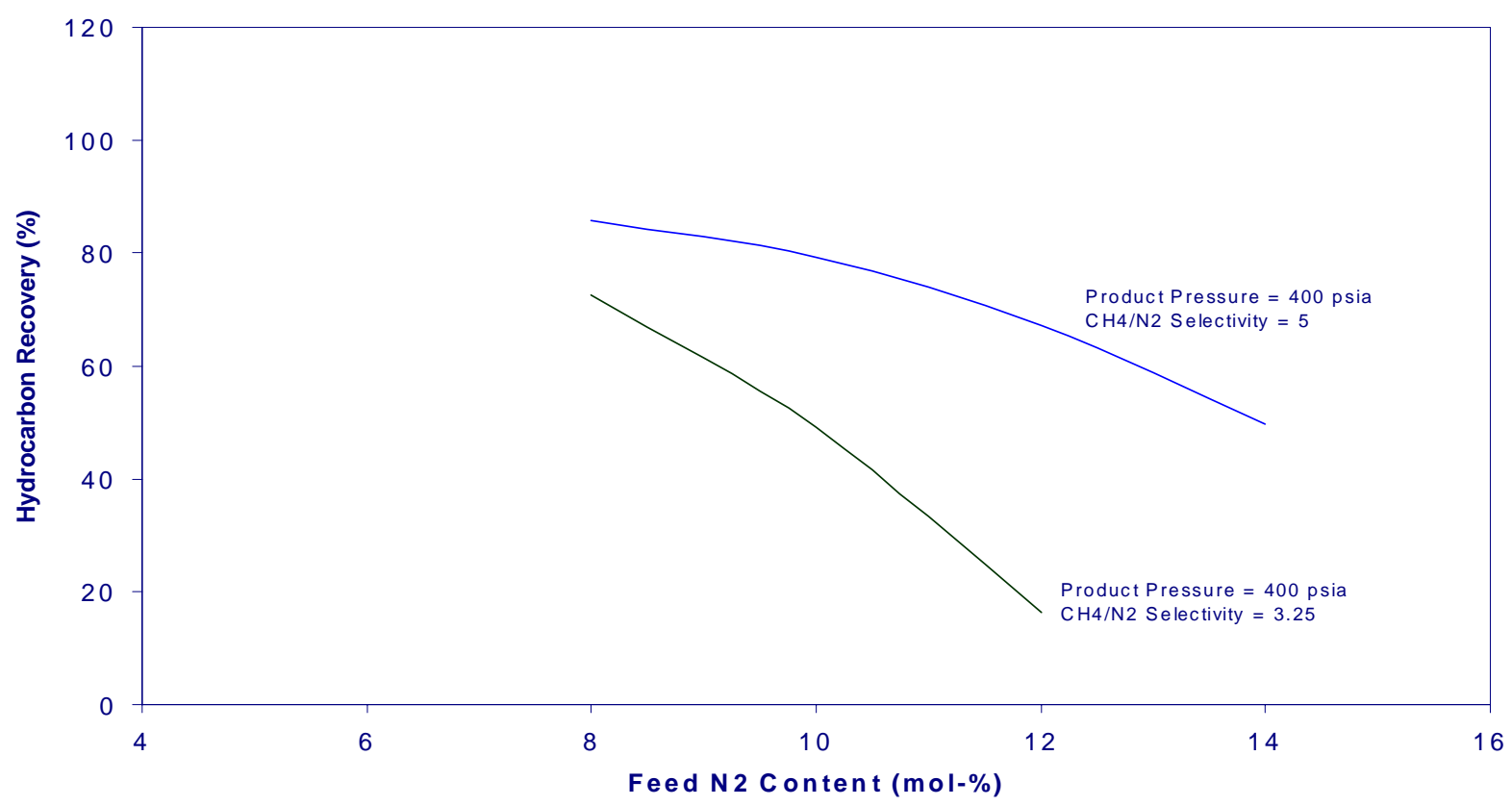

Figure 22. Effect of nitrogen feed content on recovery of hydrocarbons from the feed gas.

The economic analysis of the stand-alone cryogenic process and the combined methane/cryogenic process is based on cryogenic data provided in a recent paper presented at the Nashville GPA (Gas Processor Association) meeting by Purvin and Gertz, Kellogg Brown and Root, and the Gas Research Institute. Figures 23 and 24 compare the capital and processing costs of the individual and combined processes. As shown in Figure 23, the capital cost of the stand-alone cryogenic process is about $\$ 4$ million, whereas the stand-alone membrane process costs $\$ 200,000$. When the two are combined, the total process cost is about $\$ 2.0$ million. Put this way the stand-alone membrane process appears to be the best choice because of its very low capital cost. But the stand-alone membrane process only recovers about $20 \%$ of the feed gas whereas the stand-alone cryogenic process or combination process both achieve recoveries of greater than 95\%. Similarly, as discussed below, the combined 
process results in greater overall product recovery and lower processing costs than either process used alone.

Figure 24 shows the processing cost as a function of required product pressure for the three cases: a stand-alone membrane process, a stand-alone cryogenic process, and a combination process. All three designs were compared at a feed nitrogen content of $12 \mathrm{~mol} \%$. As discussed above, Figure 24 shows that the processing cost of a stand-alone membrane process is very high at this feed composition due to low recovery of the hydrocarbons. The figure also shows that, although the processing cost for a stand-alone cryogenic process is lower at this nitrogen content, it is still in the range \$0.8-0.95/Mscf. However, when these two processes are combined, by using a membrane process as a bulk separation step and a cryogenic process for final polishing, the overall processing costs are reduced significantly, to $\$ 0.35-0.45 / \mathrm{Mscf}$, which is well within the economically competitive range.

The reason for this synergy is as follows. The stand-alone membrane process suffers from high processing costs because the low recovery of the hydrocarbon results in a high shrinkage cost. The high processing costs of the stand-alone cryogenic process result from a high capital investment, which leads to high capital recovery factors in the processing cost. In the combined process, the membrane process provides bulk separation of the hydrocarbons so that the volumetric flow handled by the cryogenic process decreases substantially. The lower condensation load and reduced methane content in the feed gas to the cryogenic unit decreases its capital cost. At the same time, the addition of the cryogenic unit increases the total hydrocarbon recovery to more than $95 \%$, which counteracts the shortcoming of the membrane process. Thus, the combination process not only provides high recovery of the hydrocarbons but also reduces capital cost. The significant synergy of the process is reflected in the lowered processing costs. 


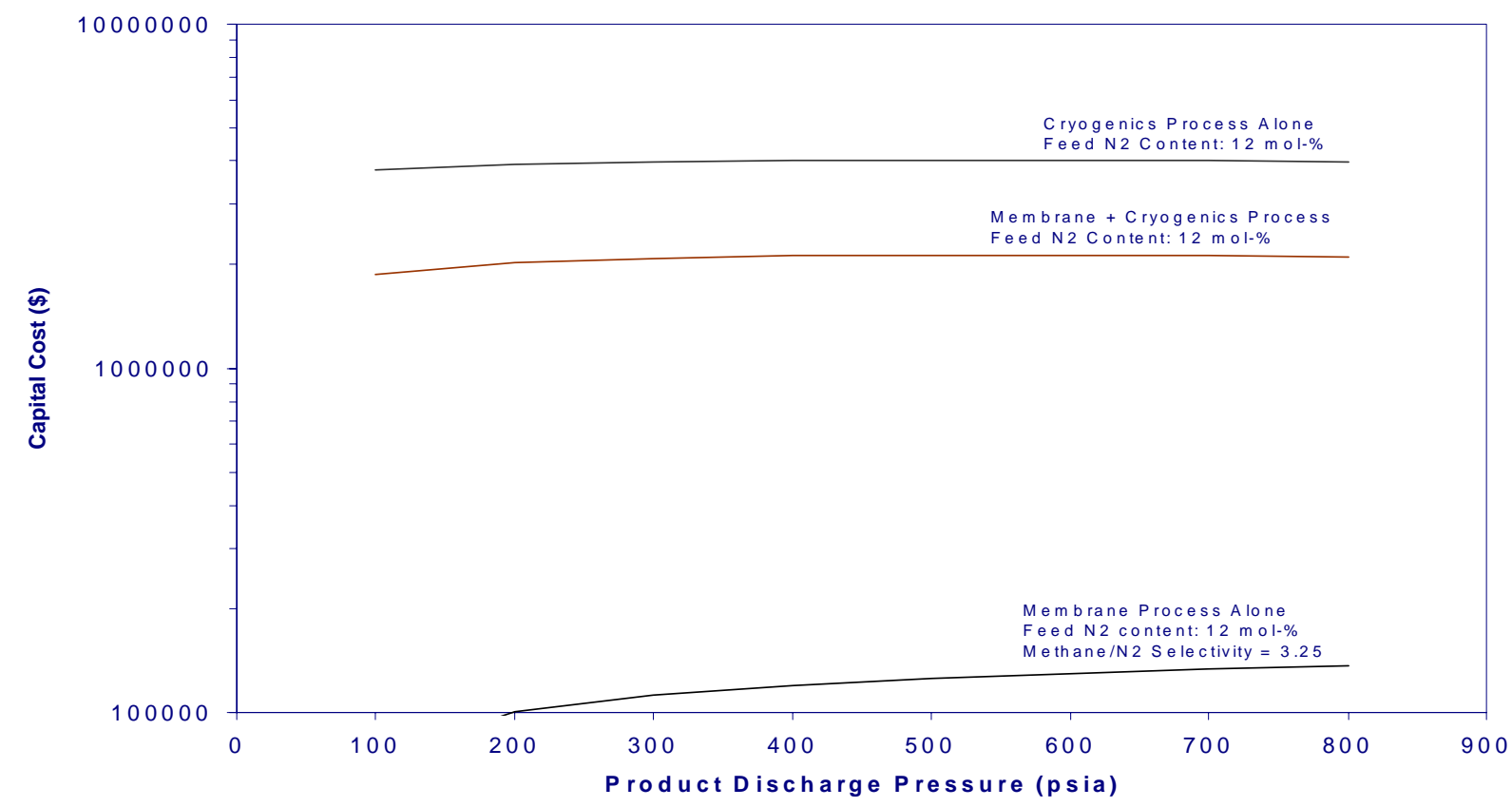

Figure 23. Comparison of the capital cost of three process configurations: a stand-alone membrane process, a stand-alone cryogenic process, and a combined membrane/cryogenic process.

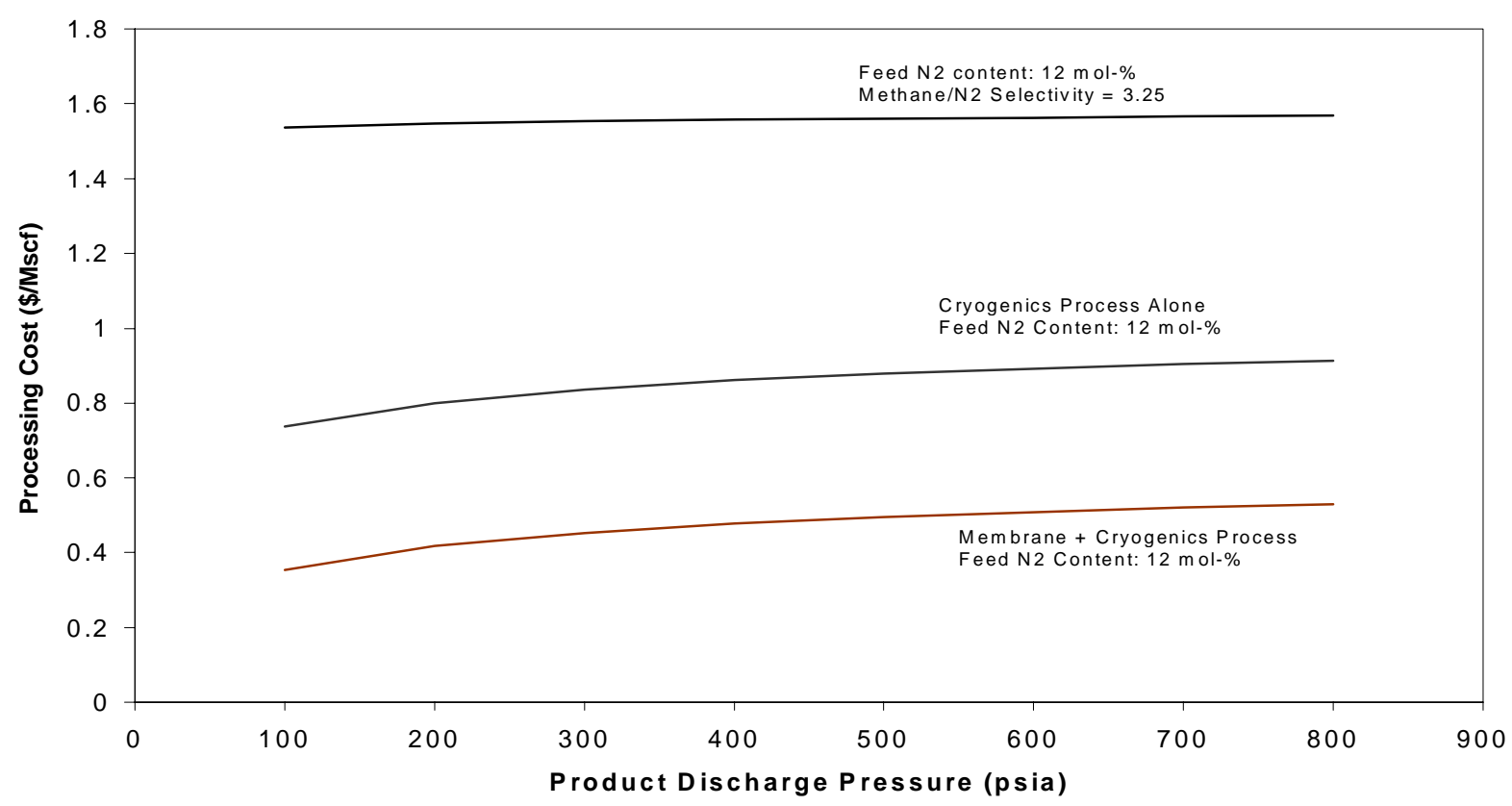

Figure 24. Comparison of processing costs for three processes: a stand-alone membrane process, a stand-alone cryogenic process, and a combined membrane/cryogenic process. 
The processing costs of the three processes as a function of feed nitrogen content are compared in Figure 25. Again, the impact of membrane selectivity and of using individual and combined processes is shown. The plot shows that, as the feed nitrogen content increases beyond about 8 mol\%, processing costs increase very rapidly for the stand-alone membrane process, especially for a membrane with a methane/nitrogen selectivity of 3.25. The processing costs of the stand-alone cryogenic process also increase but to a lesser extent. In any case, the processing costs for both standalone processes are more than $\$ 0.8 / \mathrm{Mscf}$, which is likely to be uneconomical. On the other hand, the economics of the combined process are interesting. The processing costs are in the range $\$ 0.25$ 0.4/Mscf, which is likely to be much more acceptable to operators. However, the processing costs still increase with increasing nitrogen content. Depending on the gas composition and the desired nitrogen specification in the product, we believe that the combination process may be economically feasible for feed nitrogen contents of up to 16-20\%. Beyond that concentration, the membrane process cannot recover enough methane to impact the capital cost of a cryogenic plant, so the processing costs would escalate rapidly.

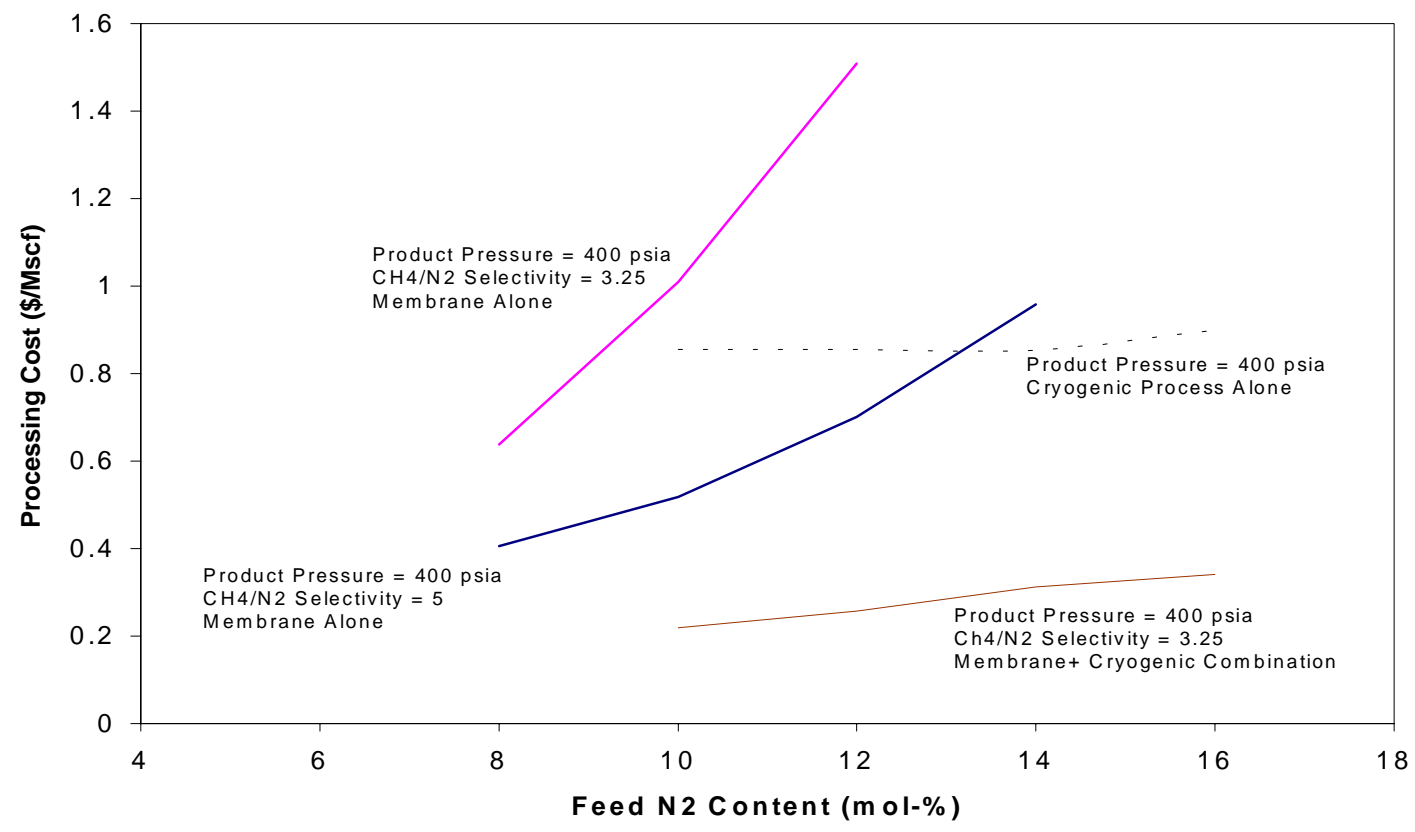

Figure 25. Comparison of processing costs as a function of feed nitrogen content for three processes: a stand-alone membrane process, a stand-alone cryogenic process, and a combined membrane/cryogenic process.

\subsubsection{Other Combination Processes}

Other technologies that are under consideration for this separation are pressure swing adsorption (PSA) and absorption. ${ }^{4,20}$ A membrane unit could also be combined with these technologies. 
Membrane/PSA Process: In the PSA process, the methane and higher hydrocarbons are adsorbed onto a suitable molecular-sieve bed while the nitrogen is rejected. Once the bed is saturated with hydrocarbons, it is regenerated by pressure swing. The collected low-pressure gas is compressed to pipeline pressure. Although the nitrogen produced by this process is pure at the top of the bed as the nonadsorbed material, the desorbed hydrocarbon product may be contaminated with nitrogen. In such cases, additional adsorption beds may be required to purify the gas to pipeline specifications. A potential combined membrane/adsorption design is shown in Figure 26. The membrane process is used for bulk separation of the hydrocarbons in front of the PSA system, thereby reducing the size and complexity of both. The membrane permeate is combined with the product from the PSA bed and compressed to the pipeline specification.

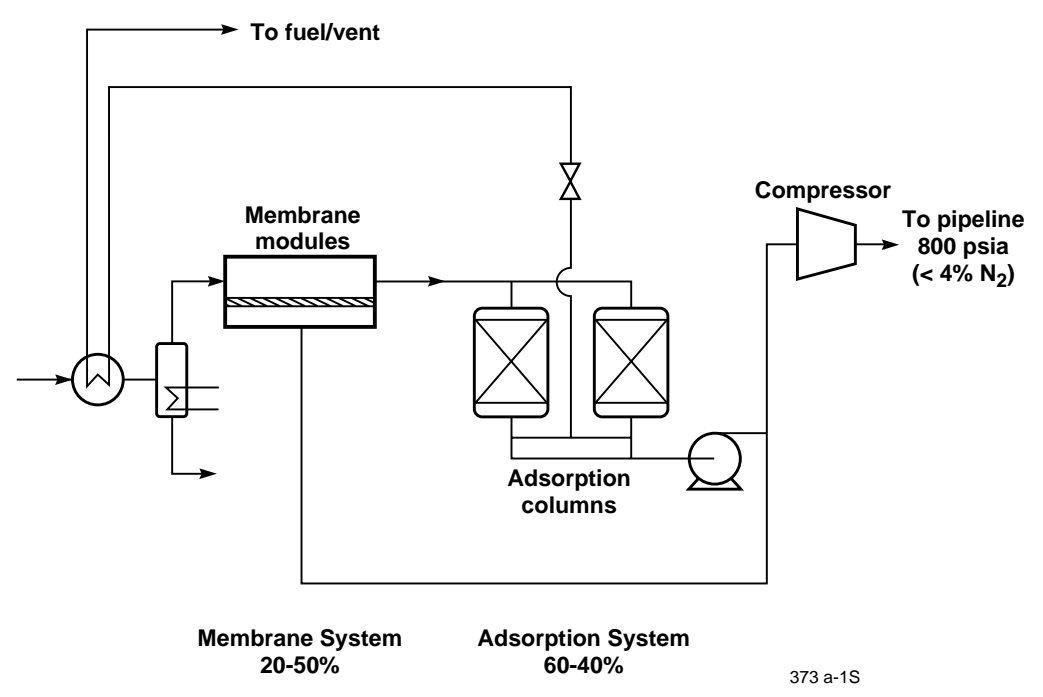

Figure 26. Combined membrane/adsorption process for methane/nitrogen separation.

Membrane/Absorption Process: This process, shown schematically in Figure 27, combines a membrane system as a pretreatment/bulk separation step with lean oil absorption for further recovery of methane and other hydrocarbons from the membrane residue stream. The membrane process reduces the volume of the feed gas by approximately $50 \%$ by preferentially removing methane. The nitrogen-rich residue stream is cold and at pressure, which are ideal conditions for the absorption process. Thus, the membrane and absorption processes both work in their optimum operating range. The internal refrigeration used to cool the gas going to the membrane stage is used advantageously by the absorption stage because both work most efficiently at low temperatures. 


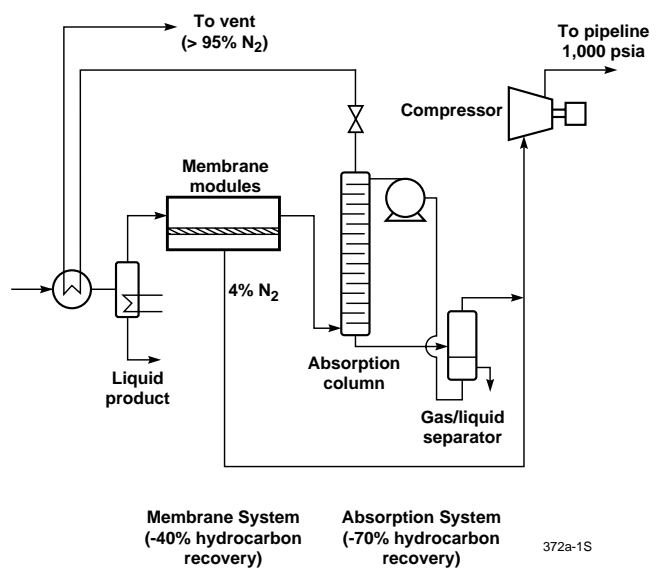

Figure 27. Process combining a single-stage membrane system with an absorption process for treating low-flow, high-nitrogen-content natural gas.

For these combined processes-membrane/PSA and membrane/absorption-to be technically feasible, the product gas must meet pipeline specifications for nitrogen. As discussed in the analysis of the membrane/cryogenic combination process, the membrane process can only produce a sufficiently high quality permeate for the polishing process with feed gas containing up to 14-18 mol\% nitrogen. Therefore, the extent of the application of these processes will be determined by the gas composition.

\subsubsection{Size of Denitrogenation Application}

To identify and classify natural gas formations and fields prone to nitrogen contamination, we performed a survey based mainly on the gas composition database prepared by Energy and Environmental Analysis Inc. for the Gas Research Institute. ${ }^{2}$ The data that relate to natural gas classified as low-quality due to the presence of nitrogen are summarized below.

In 1988 , about $26 \%$ of the total natural gas production of 14 trillion cubic feet (TCF) was low-quality due to the presence of either or both carbon dioxide and nitrogen. About one-third of this $26 \%$ was subquality due to nitrogen concentrations higher than $4 \%$. Of a total of 143 TCF of known natural gas reserves in 1988, 34\% was subquality. Of this, $40 \%$, or about $14 \%$ of the total reserves of 143 TCF, was subquality due to high nitrogen content. Thus, in 1988, about $9 \%$ of the production was subquality in nitrogen content, and about $14 \%$ of the reserves were classified as subquality with respect to nitrogen.

Figure 28 shows the distribution of nitrogen concentration as a function of the volume of the reserves. As shown, the concentration of nitrogen in subquality natural gas can be as high as $20 \%$, and the majority of the contaminated reserves contain between 5 and $18 \%$ nitrogen. As discussed in the previous sections, the entire range of these concentrations can be effectively treated to produce 
pipeline quality natural gas using a stand-alone membrane process or a membrane process combined with another technology.

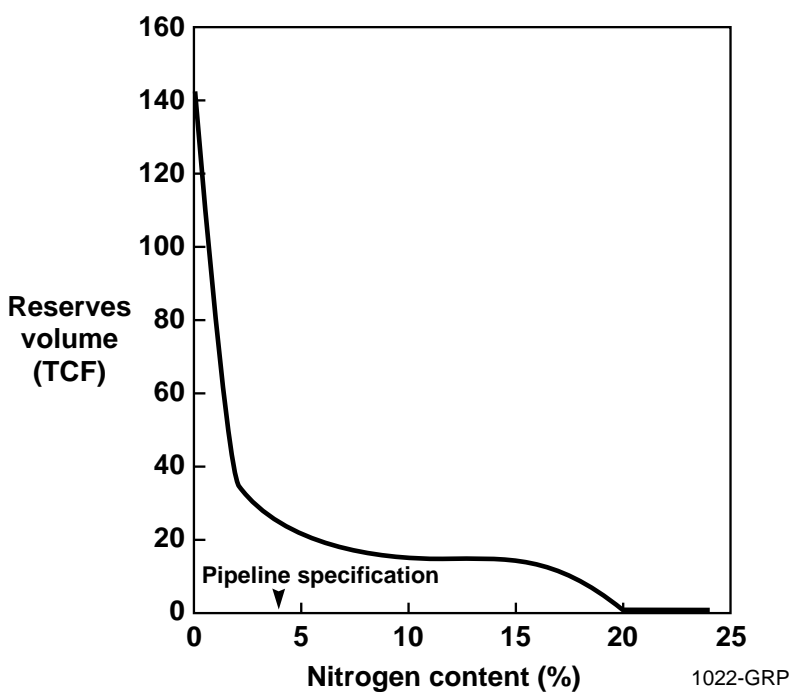

Figure 28. Reserves volume as a function of nitrogen concentration in natural gas. Nitrogen concentrations more than $4 \%$ are considered subquality.

Table 8 gives the regional distribution of the high-nitrogen reserves in non-associated natural gas. As the table shows, the major nitrogen-prone reserves are located in the Mid-Continent and the Rocky Mountain Foreland regions. In the Mid-Continent region, the Anadarko basin, including the Hugoton field, is the most important area of nitrogen occurrence, with the nitrogen being concentrated in the Permian and Pennsylvanian sections and the Hugoton Embayment area. In the Rocky Mountain area, high nitrogen occurs with high carbon dioxide and hydrogen sulfide in the Paleozoics of the Green River Basin area. Newer fields are expected to be mostly in formations in the Mid-Continent and Rocky Mountain regions. The formations in these regions contain substantial amounts of subquality gas due to the presence of nitrogen. Therefore, as these formations are exploited, the need for nitrogen removal equipment will increase. ${ }^{21,22}$

Table 8. Distribution of Non-Associated Gas with 4\% or More Nitrogen in 1988 Reserves. ${ }^{2}$

\begin{tabular}{||l|c||}
\hline \multicolumn{1}{|c|}{ Region } & $\begin{array}{c}\text { High Nitrogen Natural } \\
\text { Gas (TCF) }\end{array}$ \\
\hline Mid-Continent & 15.31 \\
Rocky Mountain Foreland & 3.61 \\
Arkla-East Texas & 1.67 \\
Permian Basin & 0.94 \\
West Coast Onshore & 0.89 \\
Williston Basin & 0.4 \\
Midwest & 0.3 \\
Appalachia & 0.1 \\
\hline
\end{tabular}




\subsubsection{Currently Installed Plants for Nitrogen/Methane Separation}

The location of plants with installed nitrogen rejection units (NRUs) in the Lower 48-states before 1985, in the late 1980s, and in the 1990s are listed in Tables 9, 10 and 11, respectively. The tables also show whether the plant has a helium recovery unit (HRU) and/or practices enhanced oil recovery (EOR).

Table 9. Plants Installed with Nitrogen Rejection Units in the United States Before 1985.

\begin{tabular}{||l|c|c|c|c||}
\hline \multicolumn{1}{|c|}{ Plant } & State & $\begin{array}{c}\text { Capacity } \\
\text { (MMscfd })\end{array}$ & NRU & HRU \\
\hline Bushton & Kansas & 950 & No & Yes \\
\hline Liberal & Kansas & 800 & Yes & Yes \\
\hline Sherhan & North Texas & 250 & Yes & Yes \\
\hline Scott City & Kansas & 168 & Partial & Yes \\
\hline
\end{tabular}

Table 10.Plants Installed with Nitrogen Rejection Units in the United States by the Late 1980s.

\begin{tabular}{||l|c|c|c|c||}
\hline \multicolumn{1}{|c|}{ Plant } & State & $\begin{array}{c}\text { Capacity } \\
\text { (MMscfd) }\end{array}$ & EOR & HRU \\
\hline Shute Creek & Wyoming & 600 & No & Yes \\
\hline Anschutz Ranch & Wyoming & 240 & Yes & No \\
\hline Jay & Florida & 90 & Yes & No \\
\hline Fordoche & Louisiana & 35 & Yes & No \\
\hline Como & East Texas & 22 & No & No \\
\hline Crane & West Texas & 20 & Yes & No \\
\hline Binger & Oklahoma & 20 & Yes & No \\
\hline \hline
\end{tabular}


Table 11. Plants Installed with Nitrogen Rejection Units in the United States in the 1990s.

\begin{tabular}{|c|c|c|c|}
\hline Plant & State & $\begin{array}{l}\text { Capacity } \\
\text { (MMscfd) }\end{array}$ & $\overline{\mathrm{HRU}}$ \\
\hline Ulysses & Kansas & 450 & Yes \\
\hline Satanta & Kansas & 220 & Yes \\
\hline Sunray & Texas Panhandle & 200 & Yes \\
\hline Fain & Texas Panhandle & $140(65)$ & Yes \\
\hline Lisbon & Utah & $80(18)$ & Yes \\
\hline Lakin & Kansas & 80 & Yes \\
\hline Baker & Oklahoma & 75 & Yes \\
\hline Eustace & East Texas & $70(30)$ & No \\
\hline Cheyenne Wells & Colorado & 35 & Yes \\
\hline Texarkana & Arkansas & 25 & No \\
\hline Jones Estate* & West Texas & 15 & No \\
\hline Shafler Lake* & West Texas & 15 & No \\
\hline Fullerton* & West Texas & 15 & No \\
\hline Keyes & Oklahoma & 14 & Yes \\
\hline Mist Field & Oregon & 7.5 & No \\
\hline Petrolia & North Central Texas & 6 & No \\
\hline Panther Creek* & North Central Texas & 3 & No \\
\hline Archer* & Colorado & 3 & Yes \\
\hline
\end{tabular}

*PSA unit

HRU: Helium Recovery Unit

EOR: Enhanced Oil Recovery

The data in these tables were obtained from the 1999 GPA proceedings paper by Purvin and Gertz. Several interesting facts emerge from the tables. Of the 26 plants containing nitrogen removal processes, four areas, namely Hugoton (11 plants), Permian basin (4 plants), Arkla Tex (3 plants), and South West Wyoming (3 plants), have a majority of the installations. The other seven identified areas with higher nitrogen have only five plants installed. It is likely that production and drilling is curtailed in these areas to allow the high-nitrogen-content gas to be blended. Clearly, as production increases in these areas, NRUs will be required to process the additional nitrogen-contaminated natural gas.

In earlier years, most denitrogenation was performed by cryogenic distillation plants processing large volumes of gas. ${ }^{18,19}$ More recently, the nature of gas processing seems to be changing, with plants of substantially lower flow capacity being installed ${ }^{5,23}$ and technologies other than cryogenic being tried. 
These trends are probably due to the increase in gas production from smaller formations with lower throughputs. We believe this trend will continue, particularly in those regions where NRUs are not yet installed. This creates an opportunity for newer technologies with reduced processing and capital costs. The proposed membrane/cryogenic combination process is a potential candidate.

\subsection{Case Studies/Customer Contact}

\subsubsection{Industry Contacts During the Program}

A number of companies and individuals, as listed in Table 12, were contacted during the project to identify potential field sites and to gather more information on the natural gas denitrogenation market.

Table 12. List of Companies Contacted During Project.

\begin{tabular}{||l|c|c|c|c|c|c||}
\hline \multicolumn{1}{|c|}{ Gas Company } & $\begin{array}{c}\text { Feed Pressure } \\
\text { (psia) }\end{array}$ & $\begin{array}{c}\text { Feed } \\
\text { Nitrogen } \\
\text { Content } \\
(\mathrm{mol} \%)\end{array}$ & $\begin{array}{c}\text { Feed Flow } \\
\text { Rate } \\
\text { (MMscfd) }\end{array}$ & $\begin{array}{c}\text { Product } \\
\text { Pressure } \\
\text { (psia) }\end{array}$ & $\begin{array}{c}\text { Product } \\
\text { Nitrogen } \\
\text { Content } \\
(\mathrm{mol} \%)\end{array}$ & $\begin{array}{c}\text { Product } \\
\text { Net } \\
\text { Heating } \\
\text { Value } \\
\text { (Btu/scf) }\end{array}$ \\
\hline MFC Drilling & 965 & 15.5 & 0.2 & 100 & 7 & - \\
\hline Clermont & 600 & 9 & 3 & 200 & 4.8 & - \\
\hline Kansas & 560 & 18.6 & 0.3 & 50 & - & - \\
\hline Petro Drilling & 1400 & 22.9 & 0.92 & 50 & 6.5 & Min 935 \\
\hline \begin{tabular}{|l} 
E.M. Smith Technical \\
Services
\end{tabular} & 500 & 16.9 & 0.1 & 275 & 3 & Min 1030 \\
\hline Greenergy & 600 & $>20$ & $>5$ & $800-1000$ & 3 & $950-1050$ \\
\hline $\begin{array}{l}\text { Bridwell Oil } \\
\text { Exploration }\end{array}$ & 750 & 34 & 2 & $>800$ & 3 & $950-1050$ \\
\hline Northstar Resources & 1000 & $15-20$ & 1 & 200 & $<8$ & - \\
\hline Crimson Resources & $>1000$ & $15-20$ & 1 & 200 & $<8$ & - \\
\hline Silverado Energy & $800-1000$ & $15-20$ & 1 & $200-300$ & $<8$ & - \\
\hline Butcher Energy & 560 & $17-18$ & 0.5 & $20-25$ & $<6$ & - \\
\hline Osborne Energy & 200 & $9-10$ & 1 & $170-200$ & $<5$ & - \\
\hline Enron/PDU & 60 & $6-10$ & 0.25 & 25 & 6 & - \\
\hline \hline
\end{tabular}

The operators listed are located mainly in the Ohio and ArklaTexas regions. These operators are predominantly small gas companies producing small amounts of gas. Most of these operations have fewer than 10 regular full-time employees and are owned and operated by individuals. Most of these 
operators are prospecting for oil and good quality gas and have discovered, much to their dismay, gas containing nitrogen that cannot be sold to the pipeline. Because these are individuals or small companies, their financial resources are limited and are used preferably to drill more wells rather than to process subquality gas to make it marketable. In effect, most of these operators are aiming to recover their lost drilling expenses at the lowest possible cost.

An interesting observation is that the operators consider the drilled wells a sunk cost and are willing to accept relatively low gas recoveries, even of the order of about $50 \%$, provided the capital cost of the system is low. In a sense, because the gas cannot be produced and is therefore of no value to them, they are willing to take low recoveries and to burn the remaining gas provided the expense involved will still allow them to make a profit.

The last name on the list, Enron/PDU, is a large energy company. Interestingly, their application is for a gas client wanting to use natural gas in a fuel cell to produce continuous power. However, the feed gas contains 6-7\% nitrogen, which is not acceptable. Therefore, they are looking at conditioning the gas to allow the customer to use their natural gas in the fuel cell. We are continuing to work with them on developing this application further.

Apart from these small companies we have also been in contact with Process System International (PSI), Boston, MA to develop strategies for combining membranes with cryogenics. PSI is a major supplier of Cryogenic Cold Boxes for various applications in the petrochemical and natural gas industries. Additionally, we have discussed this application with major oil and gas companies, including Chevron, Phillips Petroleum and Shell.

\subsection{Patents}

Four patents were filed and issued during the course of this Phase I/Phase II project:

1. "Methane/Nitrogen Separation Process," U.S. Patent 5,699,958 (September 1997).

2. "Membrane-Augmented Cryogenic Membrane/Nitrogen Separation" U.S. Patent 5,647,227 (July 1997).

3. "Separation of Low Building Gases Using Superglassy Membranes," U.S. Patent 5,688,307 (November 1997).

4. "Natural Gas Treatment Train,” U.S. Patent 5,964,923 (October 1999).

We believe these patents, together with MTR's existing natural gas patent portfolio, give good protection to the technology developed in this project and will assist in successful commercialization of the technology. 


\section{CONCLUSIONS}

We have drawn the following conclusions from the results of the work performed in this project, including the experimental data, the process design studies, the technical and economic analysis and the customer contacts.

1. Separation of methane and nitrogen is challenging for any technology because these gases are similar in size, boiling point and chemical nature. Conventional processes such as cryogenic distillation and PSA are in use, but although 26 plants have been installed in the United States, application of these technologies is not widespread. This is because the costs of nitrogen removal from subquality gas increase the capital and operating costs of natural gas processing to a point at which the economics are too poor. Most plants that practice nitrogen rejection were built for dual use, such as production of helium and production of carbon dioxide for EOR applications. In these cases, the costs of separating nitrogen are shared by a number of products, making the process feasible.

2. The use of membrane separation offers some significant advantages in this application. Lower capital costs and the ability to process small volumes of gas are the two main concerns of operators that need technology for nitrogen rejection. Both issues can be addressed by a membrane process. However, a viable membrane process requires a membrane with adequate selectivity for methane over nitrogen. Our Phase I work showed that by selecting an appropriate polymer material for the membrane and operating at low temperatures, the selectivity of 4-6 required for an economically viable process can be achieved. However, the Phase II work showed that, although the membrane selectivity does increase with decreasing temperature, the target selectivity of 5 or more was not achievable in our current membrane modules. Additionally, the materials with the most promising properties for this separation, superglassy polymer materials such as PTMSP and PMP, were found to be unstable for longterm operation in this application. Therefore, our current best membrane is silicone rubber, which was always a good candidate for this separation due to its special characteristics. The highest methane/nitrogen selectivity obtained with silicone rubber modules was between 3 and 4 ; higher selectivities, up to 4.5 , could be obtained by operation at low enough temperatures. However, this still does not meet the selectivity required to make the process widely applicable, although it is enough for certain applications, as described below.

3. Based on the properties of the currently available silicone rubber modules, our economic analysis showed that the membrane process is competitive as a stand-alone process for feed gas containing up to $10 \mathrm{~mol} \%$ nitrogen. At this low nitrogen content, the process will produce a pipeline-quality product with adequate levels of methane recovery. At higher nitrogen contents the economics of a stand-alone membrane process are poor because of low methane recovery. For nitrogen contents of $4-10 \%$, the stand-alone membrane process offers very low capital costs, between $\$ 50$ and 100/Mscfd, and processing costs of $\$ 0.4-0.7 / \mathrm{Mscf}$. In the same nitrogen content range, a stand-alone cryogenic process will have capital costs of $\$ 800$ $1,200 / \mathrm{Mscfd}$ and processing costs of \$0.8-1.0/Mscfd. 
4. Based on our economic analysis, we have determined that combining a membrane process with a cryogenic process will reduce costs significantly. The main drawback of the cryogenic process is the high capital cost, and for a membrane process the modest methane recovery rates. By combining these two technologies so that the membrane process performs a bulk separation of nitrogen and methane, and the cryogenic process is used to polish the membrane residue stream and increase methane recovery, both capital and processing costs are reduced significantly. Our calculations show that the combined process will have capital costs in the range \$400-500/Mscfd and processing costs of \$0.35-0.5/Mscf for gas containing 10-20\% nitrogen. At these costs, the economics of the process will be competitive for many more applications.

5. Based on studies of the nature of the market and the current installations, we conclude that applications for methane/nitrogen separation technology fall broadly into two categories. In the first, very large volumes of natural gas (>100 MMscfd) are processed in an integrated facility that produces not only pipeline quality natural gas but also helium, carbon dioxide and NGL products. For such applications a stand-alone cryogenic process or perhaps a combination membrane/cryogenic process are appropriate. Where a stand-alone cryogenic process is already in use, the membrane process would be integrated into the overall process only if capital and process costs were significantly reduced. The pipeline specifications would also have to be met. In the second applications category, the flow rates of the gas to be processed are much smaller, less than $10 \mathrm{MMscfd}$. In this range, the applications are numerous but the cost of processing such low volumes of gas is high. Therefore, a standalone membrane process or a combined membrane/cryogenic or membrane/PSA process could be considered. The addition of a membrane process does seem to offer significant synergies in these smaller through-put applications. However, the market or industry for these applications comprises small independent oil and gas producers, which have little or no capital for additional processing equipment. Therefore, they prefer to lease or toll-process the gas leaving the capital cost to be supplied by the equipment vendor or an intermediary. Additionally, the short lifetimes of the wells from which the gas is produced require the equipment to be moved from one location to another.

6. In summary, the potential market for nitrogen rejection equipment is large. Based on reserves volumes, the total value of gas that can be recovered with appropriate technology is about U.S. $\$ 30$ billion. Production of only $5 \%$ of the currently projected annual increase in natural gas demand in the Lower-48 states from previously unexploited high-nitrogen content wells translates to about $120 \mathrm{MMscfd}$ of production from such formations. This flow volume represents a total annual equipment market of U.S. \$30-50 million, of which about half will be for small systems processing less than $5 \mathrm{MMscfd}$. This represents a significant market for membrane systems. 


\section{REFERENCES}

1. D. Leppin and H.S. Meyer, "Gas Research Institute Program in Natural Gas Processing," GRI, SPE 21505, presented at SPE Gas Technology Symposium, Houston, TX (Jan. 23-25, 1991).

2. R.H. Hugman, E.H. Vidas and P.S. Springer, "Chemical Composition of Discovered and Undiscovered Natural Gas in the U.S. Lower-48," Executive Summary, GRI, Tightsands and Gas Processing Dept. (March 1993).

3. C. Tannehill, J.F. Strickland, and H. Meyer, "High Nitrogen Gas-Snapshot of the Present Requirement for the Future," presented at GPA Meeting, Nashville, TN (1999).

4. Y.R. Mehra, G.C. Wood and M.M. Ross, "Noncryogenic Nitrogen-Rejection Process Gets Hugoton Field Test," Oil and Gas Journal, 91, 21 (May 24, 1993).

5. R.C. Butts and K. Chou, BCCK Engineering Inc., Midland, TX Product Bulletin, "Improvements in Nitrogen Technology Prove Economical for Natural Gas Streams."

6. S. A. Stern, "Polymers for Gas Separations: The Next Decade," J. Memb. Sci. 94, 1 (1994).

7. W.J. Koros and G.K. Fleming, "Gas Separation Using Membranes Thin Film Composite Membrane," Membrane Based Gas Separations, Annual Reviews of Memb. Sci., Vol. I, 1, Elias Klein (ed.), NAMS (1993).

8. T.H. Kim, W.J. Koros, C.R. Husk, and K.C. O'Brien, "Relationship Between Gas Separation Properties and Chemical Structures in a Series of Aromatic Polyimides," J. Memb. Sci. 37, 45 (1988).

9. M.R. Coleman and W.J. Koros, "Isomeric Polyimides Based on Fluorinated Dianhydrides and Diamines for Gas Separation Applications,” J. Memb. Sci. 50, 285 (1990).

10. K. Tanaka, H. Kita, M. Okano, and K. Okamoto, "Permeability and Permselectivity of Gases in Fluorinated and Non-Fluorinated Polyimides," Polymer 33, 585 (1992).

11. C.D. Landahl and D.L. Klass, "Upgrading High-Nitrogen Natural Gas by Selective Membrane Permeation," presented at Symposium on Membrane Gas Separations for Chemical Process and Energy Applications, AIChE Spring Meeting, Houston, TX (April 5-9, 1981).

12. S.A. Stern, V.M. Shah, and B.J. Hardy, "Structure Permeability Relationships in Silicone Polymers," J. Polymer Sci: Polymer Physics Ed. 25, 1263 (1987). 
13. H.D. Shoemaker, C.J. Brinker, and R. Sehgal, "Fundamental Studies for Sol-Gel Derived Gas-Separation Membranes," Proceedings of the Natural Gas RD\&D Contractors Review Meeting, Volume II, p. 409, Baton Rouge, LA, (April 1995).

14. T. Masuda, E. Isobe and T. Higashimura, "Poly [1-trimethyl (silyl)-1-propyne]: A New High Polymer Synthesized with Transition-Metal Catalysts and Characterized by Extremely High Gas Permeability,” J. Am. Chem. Soc., 105, 7473,7474 (1983).

15. S. Auvil, R. Srinivasan, and P.M. Burban, "Mechanisms of Gas Transport in Poly(1-trimethylsilyl-1-propyne)," Polymer Preprints 32, 380 (1991).

16. T. Nakagawa, T. Saito, S. Asakawa, Y. Saito, "Polyacetylene Derivatives as Membranes for Gas Separation," Gas Sep. and Purification 2, 3 (1988).

17. L.G. Toy, I. Pinnau, and R.W. Baker, "Gas Separation Process," U.S. Patent 5,281,255 (January 25, 1994).

18. S. Ruckle and L. Coalmere, "New Hugoton Gas Plant Starts Up," Oil and Gas Journal, 96, 323 (August 17, 1998).

19. M.J. Healy, A.J. Finn, and L. Halford, “U.K. Nitrogen-Removal Plant Start Up,” Oil and Gas Journal, 97, 5 (February 1, 1999).

20. Y. Mehra, "New Process Flexibility Improves Gas Processing Margins," Energy Progress, 7(3), 150 (Sept. 1987).

21. C.C. Tannehill and C. Galvin, "Business Characteristics of the Natural Gas Conditioning Industry,” Topical Report to GRI, No. GRI-9310342 (1993).

22. M.K. Changela, R.L. McKee, H. Heshan, V.K. Pathak, M.D. Quinlan, and J.F. Strickland, "Evaluation of Natural Gas Process Technology," L.W. August 7, 1996 Echterchoff and G.J. Reading (eds.) (The M.W. Kellogg Co.), Topical Report, Task 3, Vol. II., Topical Report to GRI, No. GRI-9110230 (Sept. 1990).

23. R.C. Butts, K. Chou, and B. Slator, Oil and Gas Journal 93, 11 (March 13, 1995). 